\title{
VI.
}

\section{Zur Frage der anatomischen Beziehung zwischen Akromegalie und Hypophysistumor.}

Von

Dr. G. Cagnetto,

Assistenten am Anatom.-Patholog. Institut zu Padua.

(Hierzu Tafel II und 4 Abbildungen im Text.)

Während meiner systematischen Nachforschungen über Physiologie und Pathologie der Hypophysis, hatte ich Gelegenheit, zwei Tumoren dieses Organs zu untersuchen; einer erschien als isolierte anatomische Veränderung bei einem kleinen Mädchen, das an seinem Körper sonst nichts in pathologischer Hinsicht Interessantes bot, der andere hingegen wurde bei einem Erwachsenen gefunden, bei welchem sich nach und nach sowohl am Kopfe, als an den Extremitäten jene plumpen Formveränderungen gezeigt hatten, die Marie schon seit 1886 unter dem Namen Akromegalie in einem besonderen nosologischen Bilde zu vereinigen bestrebt war.

Im ersten Falle bot der Tumor einen wirklich eigentümlichen Anblick durch die bedeutende Teilnahme der über der Sella turcica liegenden Weichteile; or hatte das Tuber cinereum und die Corpora mammillaria zerstört, überwucherte die Innenfläche der Großhirnganglien und ragte in Form einer schwammigen, gelappten, rötlichen Masse in den dritten Ventrikel hinein, dessen natürliche Grenzen durch die die genannte Höhlung ganz ausfüllende Neubildung nicht mehr erkennbar waren, da diese sich beinahe bis zur oberen Fläche des hinteren Hirnganglions erhob. Berichte über gleiche Fälle, wo von der Hypophysis ausgehende Tumoren eine so ausgesprochene Neigung zeigen, die Basis und die Höhlungen des Gehirns anzugreifen, finden sich in der Literatur ziemlich selten. Soviel ich weiß, zeigten die von Zenker ${ }^{1}$ ) vor vielen Jahren beschriebenen Neubildungen ein analoges Verhalten, feruer die Fälle

1) Zenker, Dieses Archiv Bd. XII. 
von $\operatorname{Rath}^{1}$ ), won Hippel ${ }^{2}$ ), von Pechkranz ${ }^{3}$ ) and neuerdings von Socat).

Nicht geringere Wichtigkeit hatte der zweite Fall. Uber denselben existiert eine ausführliche klinische Abhandlung von Baggi $0^{5}$ ), dem der Fall gehörte, und ich verdanke es ihm und dem Prosektor Cavagnis, daß ich den bezüglichen Hypophysistumor und einige unerwarteterweise gefundene metastatische Knoten untersuchen konnte. Ober diese anatomischen Veränderungen enthält die erwähnte Arbeit nur einen allgemeinen histologischen Bericht. Da das Gewebe des Gehirnanhangs bei den Akromegalischen ein noch strittiges Argument abgibt, mag eine genauere mikroskopische Untersuchung dieses Falles vielleicht interessante Daten zu dieser Frage bieten.

Die mit der Vergrößerung der Hypophysis einhergehenden schweren Formveränderungen an den Gliedern und am Schädel wurden schon vor dem Jahre 1886 von Verga $a^{6}$ ), Brigidi ${ }^{7}$ ), Henrot ${ }^{8}$ ), Fritsche und Klebs ${ }^{9}$ ) konstatiert, aber für zufällig gehalten, nur Marie hat auf den nicht zufälligen Zusammenhang dieser Erscheinungen hingewiesen; er hat sogar die Hypothese aufgestellt: die Akromegalie sei die Folge einer durch mangelhaftes Funktionieren der Hypophysis hervorgerufenen Stoffwechselstörung. So entstand die sogenannte „HypophysisTheorie" mit ihren Anhängern und Gegnern.

Seit Maries Bericht bis zum Jahre 1892 betonen alle über die Beziehungen zwisehen Akromegalie und Hypophysistumor handelnden Veröffentlichungen nur die Volumveränderungen des Hirnanhangs und die topographischen Abweichungen, ohne weder die besondere Struktur des Tumors zu beachten,

1) Rath, Beiträge z. Symptomenlehre d. Geschwälste d. Hypophysis cerebri. Graefes Archiv Bd. 34.

2) Hippel, Dieses Archiv Bd. 126, S. 124.

3) Pechkranz, Neurologisches Centralbl. 1899, S. 203.

4) Soca, Iconogr. de la Salpétr., 1900, XIII, p. 101.

5) Baggio, Rivista Veneta di Scienze Mediche 1903, Fasc. 3, Febbrajo.

6) Verga, Rendiconti del R. Istituto Lombardo 1869, Vol. III.

7) Brigidi, Rendiconti dell' Accademia Medico Fisica Fiorentina 1877.

8) Henrot, Notes de Clinique Médicale. Reims 1877.

9) Fritsche u. Klebs, Beiträge zur Pathologie des Riesenwachses. Leipzig 1884. 
noch eine geeignete Erklärung über die oft bestehende Heterogenie der verschiedenen Neoplasien zu geben. Nach ihnen erhält jede, welcher Gattung auch immer angehörende Hypophysisgeschwulst ihre Bedeutung durch das Unterdrücken der Gewebsfunktion. Diese Hypothese genügt, wie man sieht, durchaus nicht zur Erklärung der zahlreichen, ohne Akromegalie vorkommenden Fälle.

In Italien hat Massalong $0^{1}$ ) als erster eine auf histologischem Befund des Hypophysistumors sich stützende eigene Theorie über die Pathogenese der Akromegalie aufgestellt, indem er der Veränderung des Hirnanhangs eine jener von Marie und seinen Schülern ganz entgegengesetzte Bedeutung beilegte. Er hält nach Feststellung der unterscheidenden Merkmale zwischen Akromegalie und anderen Knochenerkrankungen (Ostéoarthropathie hypertrophiante pneumique; Ostitis von Paget; Leontiasis ossea von Virchow) die akromegalisehen Veränderungen für eine von der Geburt an bestehende funktionelle Störung in Thymus und Hirnanhang. Diese zwei, im embryonalen Leben eine wichtige physiologische Aufgabe besitzenden Organe, die dann nach der Geburt zum langsamen Sehrumpfen und zur Atrophie bestimmt sind, sollen nach Massalongo bei den Akromegalischen bis nach der Pubertät ihre Funktion behalten können. So lange der Körper in der Entwicklung, im Wachstum ist, wird die durch anomales Andanern dieser Funktion hervorgerufene Stoffwechselstörung nicht bemerkt, weil das physiologische Wachstum die pathologischen Veränderungen verschleiert; sobald hingegen das Wachsen aufhört, das ist ungefähr gegen das 20. Jahr, erscheinen sofort die akromegalischen Symptome als Ausdruck des funktionellen Anachronismus dieser Drüsen.

Massalongo geht also von der Voraussetzung aus, daß jede Vergrößerung der Hypophysis und des Thymus bei Akromegalischen in einer durch funktionelle Weitertätigkeit entstandenen Hypertrophie besteht, während doch noch vor seiner Theorie Fälle von verspäteter Akromegalie vorkamen (die in den letzten Jahren noch häufiger beobachtet wurden), zu deren Erklärung man entweder einen besonderen Grad von Unempfind-

1) Massalong o, Riforma medica 1892, No. 157, 158. 
lichkeit gegen die Wirkung der übermäßigen thymischen und hypophysischen Absonderungen oder eine lange Pause vor der Wiederaufnahme der Funktion beider Drüsen annehmen müßte. Außerdem geht es wegen der Ontogenese und Histogenese jedes dieser beiden Organe nicht an, ein Zusammengehen während ihrer Evolution nur aus dem Grunde anzunehmen; weil manchmal beide Organe gleichzeitig verändert sind; erstens wegen der Ontogenese, weil die während der embryonalen Entwicklung ziemlich umfangreiche und wahrscheinlich eine wichtige funktionelle Bestimmung besitzende Thymusdrüse nur in den ersten extrauterinen Lebensmonaten unverändert bleibt, später nach und nach atrophisch wird und endlich bei der $\mathrm{Pn}$ bertät gänzlich verschwindet. Die Hypophysis hingegen entwickelt sich als gut individualisiertes Organ erst spät im menschlichen Embryo, denn während sie im fünften, sechsten Monate kaum in Form eines rosa-grauen Knötchens erkennbar ist, sehen wir sie gegen Ende des fötalen Lebens besonders im Vorderlappen sich vergrößern und nach der Geburt im gleichen. Schritt mit dem übrigen Körper wachsen. Es ist sogar noch etwas anderes mehr zu betonen. Sei es, dab man sich auf Schönemanns ${ }^{1}$ ) Angaben stützt, sei es, daß man die neueren Statistiken von $\mathrm{Comte}^{2}$ ) und von Caselli ${ }^{3}$ ) in Betracht zieht, man kann sich stets überzeugen, daß die Hypophysis im Wachstum so lange fortzuschreiten vermag, als die uibrigen Organe, ja noch darüber hinausgeht, da nach Schönemann die Hypophysis ihr größtes Volumen zwischen 30-40 Jahren erreicht und nach Caselli die Gewichtszunahme der augenscheinlich gesunden Hypophysis bei nicht von Veränderungen im Knochensystem befallenen Geistesgestörten noch länger dauert, und bei den Männern das Maximum zwischen der fünften und sechsten Dekade erreicht. Haller ${ }^{4}$ ) bestätigt im Grunde genommen das gleiche, wenn er an der Hypophysis keine den rudimentären Organen eigenen Anzeichen bemerkt. Betrachtet man

1) Schönemann, Dieses Archiv 1885, Bd. 129.

2) Comte, Zieglers Beiträge 1898, Bd. 23 .

3) Caselli, Studi anatomici e sperimentali sulla fisiologia della ghiandola pituitaria. Reggio Emilia, Tip. Calderini 1900.

4) Haller, Morphologisches Jahrbuch Bd. I, 1896, S. 531. 
diese Beziehungen zwischen Hypophysis und Alter, so scheint es annehmbar, daß die Bestimmung des Hirnanhangs auch in physiologischer Hinsicht von jener der Thymusdrüse abweicht. Hiervon können wir uns, wie erwähnt, auch durch das. Studium der Histogenese beider Organe überzeugen. In der Tat ist der embryonale Thymus nur zu Anfang ein Organ mit Drüsenstruktur; im fünften uterinen Lebensmonat hat er diese schon stark verändert und sich in ein lymphoides Organ (Hertwig) umgewandelt. Die Epithelzellen werden immer spärlicher, bis von ihnen nur die sogenannten "Hassalschen Körperchen" übrig bleiben (His-Stieda).

Dagegen bewahrt die Hypophysis durch das ganze Leben eine ihrer frühesten Uranlage beinahe gleiche Struktur, und was die Hauptsache ist: der Drüsenlappen behält auch im spätesten Alter noch seine Drüsennatur. Es scheint demnach, daßs Massalongos Annahme eines funktionellen Parallelismus nicht haltbar ist.

Was den Hypophysistumor der Akromegalischen betrifft, so ist die ihm von. Massalongo, im Gegensatz zu Marie, beigelegte Bedeutung interessant, da der Tumor kein Aufhören der Funktion der Hypophysis bedingen soll, sondern im Gegenteil die Wirkung ihrer über die physiologischen Grenzen hinausgehenden Tätigkeitsdauer darstellt.

Mir scheint es erlanbt, hier den Einwurf zu erheben, daß es zum mindesten sonderbar ist, wie das blobe Phänomen des spontanen Andauerns einer Funktion eine solche Größenzunahme eines Organs hervorrufen könnte, um es die ihm durch die umgebenden Knochen naturgemäß gezogenen Grenzen so weit überschreiten zu lassen, bis bedeutende Knochenzerstörungen und schwere Schädigungen der Gehirnfunktion die Folge sind. Sicherlich finden sich unter den schon vor dem Jahre 1892 erschienenen Berichten über akromegalische Hypophysistumoren einige Fälle, wie z. B. jener von Henrot (a. a. 0.), in denen die schweren Formveränderungen der Hypophysis, die über die Kapsel hinausgehende ungeheure Geschwulst und eine gewisse Neigung zur Knochenusur mehr auf ein atypisches Wachstum der Drüse, als auf eine einfache funktionelle Hyperplasie hinweisen. Die an sich richtige Voraussetzung, durch das Studium der Organ- 
veränderung am Kadaver die Ursache der Akromegalie ergründen zu wollen, sollte nicht dahin führen, dem Befund über die vorerwähnten Neoplasien der Hypophysis die ihm gebührende Wichtigkeit nicht beizumessen.

Deswegen versuchte Tamburin ${ }^{1}$ ) seine Ansicht über die Genese der Akromegalie mit den verschiedenen Befunden über den Hypophysistumor in Einklang zu bringen. Er gibt zwar mit Massalongo zu, daß das anomale Wachstum bei den Akromegalischen von einer hypophysischen Hyperfunktion abhängt, verhehlt sich aber nicht, daß in einigen Fällen der Hypophysistumor allzu ausgeprägten bősartigen Charakter zeigt, um ihn für eine einfache Hyperplasie halten zu dürfen. Seiner Meinung nach kann die Akromegalie in klinischer Hinsicht in zwei Perioden getrennt werden, denen eine verschiedene Natur des Hypophysistumors entspräche. In der ersten zeigen sich, neben gewissen geistigen und funktionellen Störungen, die hauptsächlichen Krankheitssymptome, nämlich die VergröBerung des Gesichts, der Hände and Füße und noch andere progressive Veränderungen, welche inkonstant sind. In dieser Periode äußert sich nach Tamburini ein wirklicher HypophysishyperplasieprozeB. Im zweiten Stadium kommen regressive Ernährungsstörungen zur Erscheinung, die zu einer allmählichen Erschöpfung der vegetativen und psychischen Funktionen und zum Marasmus führen. Dann ist der Hirnanhang nicht mehr von Hyperplasie befallen, sondern schon in ein neoplastisches atypisches Gewebe umgewandelt, und die darauf folgende Kachexie entsteht durch die Bösartigkeit des Hypophysistumors. Mit anderen Worten: so lange die übermäBige Funktion der Hypophysis dauert, hält die Vergrößerung der befallenen Teile gleichen Schritt, während bei bösartiger Entartung die „hypophysisfreie Kachexie" auftritt. Aus diesem Grunde ist die italienische Schule im Widerspruch mit der französischen, weil für jene die Akromegalie $a b$ initio von einer Hyperfunktion des Hirnanhangs verursacht wird.

Anch für Tamburini ist die histologische Untersuchnng

1) Tamburini, Rivista sperimentale di Freniatria e Medicina legale. Vol, XX, p. 559. 1894. Verhandlungen des internat. neurologischen Kongresses in Brüssel. September 1897. 
des Tumors für die Existenz der Hypophysishyperfunktion entscheidend. Nach der Ansicht seines Schülers Caselli (a. a. 0.) können ungelähr ein Dutzend vor dem Jahre 1900 berichtete Beobachtungen von Hirnanhangtumoren bei Akromegalischen als Bestätigung dieser Ansicht gelten. Unter diesen Fällen ist der von Tamburini mitgeteilte außerordentlich interessant, bei dem der den histologischen Typus des Hirnanhangdrüsengewebes zeigende Tumor vorwiegend von Chromophilzellen gebildet war, d. h. von jenen Elementen mit granuliertem Protoplasma, welche in gewisser Menge auch normal im Vorderlappen vorkommen. Man weiß, daß man infolge der größeren oder geringeren Zahl der Granula und der entsprechenden Färbbarkeit des Protoplasma, vor vielen Jahren die Scheidung der Epithelzellen des vorderen Lappens in zwei Gruppen angenommen hatte: in die Haupt- und schwer färbbaren, an protoplasmatischen Granula sehr armen oder sie ganz entbehrenden Zellen und in die granulabesetzten, umfangreicheren, aber spärlicheren Neben- oder chromophilen Zellen. Zuerst hat Saint-Remy') und dann Benda ${ }^{2}$ ) gezeigt, daß eine absolute und wirkliche Unterscheidung dieser Elemente in zwei in jedem Falle gut differenzierbare und mit besonderen Eigenschaften versehene Arten nicht angeht. Tatsächlich zeigten diese Autoren, daß auch die sog. Hauptzellen mit sehr kleinen, sarkoplastischen, durch besondere Methoden färbbaren Granula versehen sind, und daß man in demselben Schnitte die Zwischenzustände der nicht färbbaren und der chromophilen Zellen in ihrem fortschreitenden Ubergang ineinander beobachten kann, welche Zwischenzustände durch Elemente, in deren Protoplasma da und dort spärliche Granula entstehen, dargestellt werden. Diese sorgfältigen Beobachtungen erklären die schwerwiegende Bedeutung von Tamburins Befund. Nach ihm ist im Hypophysistumor bei Akromegalie nicht nur ab initio die Struktur des Hirnanhangvorderlappens wiedergegeben, sondern die Epithelzellen, welche die Hauptbestandteile der Neubildung ausmachen, besitzen die histochemischen Anzeichen einer Hyperfunktion: d. h. sie sind beinahe alle chromophil. Die Annahme, daß das numerische

1) Saint-Remy, Archives de Biologie, 1892.

2) Benda, Verhandl. d. physiol. Gesellschatt zo Berlin, 1900, S. 166. 
Uberwiegen der Körnchenzellen die Bedeutung einer Zunahme der angenommenen spezifischen trophischen Funktion des Organes habe, deckt sich mit Virchows ${ }^{1}$ ) alter, von Coulon ${ }^{2}$ ) nenerdings bestätigter Ansicht, nach der bei der Hypophysis der zwerghaften Cretins die Zahl der Chromophilzellen im Vergleich zu den Hauptzellen sehr spärlich ist. Dieser Hypothese schließen sich die neueren Untersuchungen von Vassale ${ }^{3}$ ) und von Benda $a^{4}$ ) an: der erstere fand bei den neugebornen Tieren die chromophilen Zellen in der Hypophysis vermehrt, wobei man nicht an Degenerationsveränderungen denken darf, und der letztere bestätigte ihr Uberwiegen in der Hypophysis junger Leute im Gegensatz zu den alten. Diese Chromophilzellen sollen hingegen in gewissen, mit Phänomenen schwerer Hypotrophie verbundenen pathologischen Zuständen (Basedows Krankheit) bedeutend vermindert sein; deshalb müßten sie für im Höhepunkt ihrer Funktion befindliche Elemente gehalten werden, wogegen die sogenannten Hauptzellen nichts anderes als im Ruhezustand befindliche Elemente darstellen. Benda ${ }^{5}$ ) hat ferner neuerdings über den nekroskopischen Befund von vier Fällen von Akromegalie berichtet, von denen in dreien der Hypophysistumor alle Übergangsstadien des noch an einigen Stellen konservierten Vorderlappens vom Drüsengewebe ins adenomatöse 'Gewebe mit größeren und an Elementen reicheren Alveolen aufwies. Im vierten Falle hatte der Tumor bereits die makroskopischen und histologisehen Anzeichen einer bösartigen Neubildung angenommen. Die chromophilen Zellen waren in allen vier Fällen zahlreich, und in zwei derselben zeigten sich schlauchartige, mit Colloidklumpen gefüllte Bildungen. Benda urteilt in Übereinstimmung mit Tamburini: die Akromegalie sei der Ausdruck und die Folge einer Hypophysishyperfunktion und die betreffenden Tumoren, wenigstens zu Anfang, hyperplastische adenomatöse Strumen. Man ist so Schritt für Sehritt zu einem Urteil gekom-

1) Virchow, Geschwülste, Vorlesung 22, 1863.

2) de Coulon, Dieses Archiv Bd. 147, 1897.

3) Vassale, Rivista sperimentale di Freniatria. Vol. 23, Fasc. 1.

4) Benda, Berliner klin. Woehenschr. 24. Dez. 1900.

5) Benda, Dentsche mediz. Wochensehr, 1901. 
men, das früher, vor den Beobachtungen von Hansemann ${ }^{1}$ ), Sehmorl ${ }^{2}$ ) and Schmidt ${ }^{3}$ ) über die Funktion der Leberadenome, den Grundgesetzen der Pathologie widersprechend geschienen hätte, nämlich einem Tumorgewebe den Wert eines funktionierenden Gewebes beizumessen. Immerhin taucht der Verdacht auf, daß es sich bei den von Tamburini unter tätige Adenome eingereihten Fällen in Wirklichkeit nur um wahre Hyperplasien oder Struma der Hypophysis ohne Ubergangsform ins Adenom gehandelt habe. Wenn es anch sehr interessant war, die Aufmerksamkeit auf die Tatsache gelenkt zu haben, daß der Hypophysistumor bei den Akromegalischen eine ganz besondere Struktur besitzt, so könnten doch gewichtige Einwendungen gegen die von Tamburini und Benda dem neugebildeten Gewebe zugeschriebene pathogene Bedentung vorgebracht werden: erstens das Vorkommen von unbedeutenden Hypophysishyperplasien bei Akromegalischen, bei denen die schweren Knochenveränderungen tatsächlich zu ihrer Ursache in keinem Verhältnis stehen. Hierher gehört z. B. der von Israel ${ }^{4}$ ) illustrierte interessante Fall von Akromegalie, wo die Hypophysis ihr mittleres Gewicht nur um 1 Decigramm überstieg, und wo bei der histologischen Untersuchung die Chromophilzellen sich "gegen den normalen Zustand nicht nachweisbar vermehrt" zeigten. Wenn man die unter normalen Umständen sich zeigenden großen Schwankungen im Volumen der Hypophysis bei Individuen derselben Altersstufe ins Auge faßt (siehe die Statistiken von Comte und von Caselli), wird der Verdacht rege, daß einige der bei Akromegalischen vorkommenden sogenannten Hypophysisadenome (Lins mayer ${ }^{5}$ ), Dallemagne 2. Fall $\left.{ }^{6}\right)$ ], die mit einer völligen Integrität des Knochengerüstes vereinbare Gewichts- und Volumengrenze äußerst wenig überschreiten. Diese Voraussetzung erhält noch mehr Geltung, wenn man bedenkt, daß große Hypophysisadenome ohne akro-

1) Hansemann, Berlin. klin. Wochenschr. 1890, No. 16.

2) Schmorl, Centralbl f. allgem. Pathologie, 1895.

3) Schmidt, Dieses Archiv Bd. 148, 1897.

4) Israel, Dieses Arch. Bd. 164, S. 344.

5) Linsmayer, Wiener klin. Wochenschrift, 1894.

6) Dallemagne, Archives de Méd. expérim. et d'anatomie pathol. 1895. 
megalische Erscheinungen vorkommen ${ }^{1}$ ), und daB sichere Fälle von Akromegalie bestätigt wurden, bei denen ein Hypophysistumor bei der Autopsie nicht Konstatiert werden konnte. Während dieser zweite Befund sich jeder Erklärung verschließt, könnte man beim ersten voraussetzen, daß die verschiedenen, micht mit Akromegalie einhergehenden Hypophysisadenome (ich kenne ungefähr ein Dutzend Fälle) in Wirklichkeit der Kategorie chromophober Zellenadenome, d. h. den nicht funktionierenden und dem von Carbone ${ }^{2}$ ) beschriebenen Tumor eines nicht akromegalischen Mannes ähnlichen Adenomen tatsächlich angehören. Ubrigens bemerke ich sogleich, daß der z. B. von Hippel (a. a. 0.) beschriebene Tumor in seinem histologischen Befund von dem durch Carbone untersuchten sich unterscheidet, denn der erstere erwähnt das Vorkommen von Colloidklumpen im Innern der Schläuche, worüber Carbone nichts berichtet, obgleich auch in Hippels Falle jede akromegalische Veränderung des Knochengerüstes fehlte. Dasselbe gilt für das Hypophysisadenom, welches Cesaris-Demel (a. a. 0 .) bei einer mit Syringomyeli behafteten und nicht akromegalischen Frau beobachtete; auch in diesem Falle wurden, obwohl der Autor sich nicht über die Existenz der chromophilen Zellen im Tumor ausspricht, Colloidklumpen in den Alveolen gefunden.

Wenn man zuletzt beachtet, $d a ß$ in vielen Fällen ohne Autopsie - das sind die meisten - und in einigen auch anatomisch untersuchten, die akromegalischen Knochenveränderungen den Symptomen des Hypophysistumors (die wegen des empfindlichen Sitzes des Organes schon frühzeitig zum Vorschein kommen müBten) lange Zeit vorausgingen, ist man geneigter, diese Neubildungen der Hypophysis nicht für idiopathische im Sinne Tamburinis und Bendas zu halten, sondern eher als von einem unbekannten, auf die Hypophysis und

1) Fälle von Loeb n. Arnold (dieses Arch. Bd. 3); Weigert (ibidem Bd. 65); Eisenlohr (ibid. Bd. 68); Weichselbaum (ibid. Bd. 75); Müller (Zeitschr. f. Med. u. Naturwissensch. Bd. 8, Hft. 3); Ribbert (dieses Arch. Bd. 90); Breitner (ibid. Bd. 93); Lawson (Transactions of the pathol. Society, p. 379); Hippel (dieses Arch. Bd. 126); Cesaris-Demel (Arch. per le Scienze Mediche 1900).

2) Carbone, Gazzetta Medica Italiana 1902. 
auf das Skelett gleichzeitig wirkenden Reiz ausgehend anzusehen [Strümpell'1), Vassale $\left.{ }^{2}\right)$, der einem abnormen Stoffwechsel entspringt. So erklärt es sich, daß der Hypophysistumor auch fehlen kann, trotzdem die akromegalischen Veränderungen des Skelettes vorhanden sind. Derselben Meinung ist seit 1894 anch Arnold ${ }^{3}$ ), der sich hierüber in der Weise ausspricht, daß die „Vergrößerung der Hypophysis eine mehr oder weniger häufige und in versehiedenen Stadien der Erkrankung auftretende Teilerscheinung sei“. Nach dem Gesagten kommt man dazu, der Hypophysis die Bedeutung eines pathogenen Faktors abzusprechen und ihre eventuelle Hyperplasie nicht als direkte Ursache der Akromegalie, sondern als nebenherlaufendes Symptom anzusehen. In diesem Falle bleibt zu entscheiden, $o b$ diese sekundäre Hyperplasie mit ihrer übermäßigen Funktion direkt zusammenhängende klinische Anzeichen aufweist, oder ob im Gegenteil diese Hyperplasie ihrerseits nur Störangen der Gehirntätigkeit hervorruft, die durch den von dem Hypophysistumor auf die Gehirnbasis ausgeübten Druck entstehen können. Diese Möglichkeit eines mechanischen lokalen Einflusses erklärt sich dureh den Sitz der Hypophysis, und man kann ihn auch für die sich langsam entwickelnden Tumoren nicht in Abrede stellen. Auch der als Enderscheinung bei den einen großen Tumor aufweisenden Akromegalischen auftretende kachektische Zustand, könnte als größtenteils von Ernährungsstörungen herrührend angesehen werden, die in dem auf die Nervenzentren durch den Tumor ansgeübten Druck ihren Grund haben.

Meiner Meinung nach ist die Hypothese, die im Hypophysistumor der Akromegalischen ein einfaches Symptom und nicht die Krankheitsursache sieht, mit den anatomischen Befunden in größerer Obereinstimmung und entspricht mit durchdringenderer Kritik den verschiedenen Bildern der Hypophysis und deren Bedeutung in den einzelnen Fällen. Diese verschiedenen Bilder könnten als Ausdruck der größeren oder geringeren Disposition des Organs, die schädigende Wirkung des

1) Strümpell, Deutsche Zeitschr. f. Nervenheilk. Bd. 11, 1897.

2) Vassale, Rif. Speriment. di Freniatria Bd. 28, Fase. 1.

3) Arnold, Dieses Archiv 1894, Bd. 135. 
abnormen Stoffwechsels zu empfinden, angesehen werden. Die Hypophysis vermag manchmal tatsächlich die Folgen dieser schweren Stoffwechselstörung ungestraft zu ertragen, sei es, daß es sich um chronische Akromegalie handelt [Arnold $\left.{ }^{1}\right)$, bei welcher wegen der längeren Krankheitsdauer sehr günstige Bedingungen für eine Schädigung des Organs vorzuliegen scheinen, sei es, daß wir es mit akuter Akromegalie zu tun haben $\left[\right.$ Waldo $\left.\left.\left.{ }^{2}\right), \mathrm{Pel}^{3}\right)\right]$, wobei man annehmen könnte, der schnelle Krankheitsverlauf sollte die Hypophysis der Möglichkeit berauben, zu reagieren. Daß die ersterwähnte Eventualität wirklich eintritt, zeigt der Fall Bonardi ${ }^{4}$ ), bei dem die voraussichtlich sehon früher sklerotische Hypophysis solche selbstständigen Strukturveränderungen aufwies, daß man versteht, wie ihre sekretorischen Zellen vom anomalen allgemeinen Metabolismus unberührt bleiben können. In anderen Fällen dagegen empfindet die Hypophysis zu heftig die Folgen des Reizes und entartet nach einem anfänglichen Zeichen von Hyperplasie und erhält cystenförmiges Aussehen [Dana $a^{5}$, Dallemagne 3. Fall (a. a. 0.)] und breiige Konsistenz (Fratnich, Linsmayer), oder das Parenchym wächst allmählich und verändert sich durch den anhaltenden mäßigen Reiz in eine atypische Neubildung, d. h. in Adenom (Tamburini, Benda) und von diesem - in seltenen Fällen - in eine wahre bösartige Geschwulst (Benders Fall Köhler). Welcher Natur diese bösartige Neoplasie sein muß, ist leicht vorauszusehen, wenn die Vermehrung der Epithelzellen am Wachstum des Tumors den Hauptanteil hat, wie dies anch die neneren Befunde Bendas bestätigen. Auf Grund derselben fühlt sich der genannte Autor zum Zweifel geneigt, ob nicht vielleicht viele über Hypophysissarkome and Angiosarkome bei Akromegalischen bisher mitgeteilte Beobachtungen vielmehr als wahre adenomatöse Strumen oder Adenokarzinome der Hypophysis angesehen werden müssen.

1) Arnold, Zieglers Beiträge Bd. X. 1891, s. 1.

2) Waldo, British medical Journal 1894 .

3) Pel, Berliner klin. Wochenschr. 1891.

4) Bonardi, Archivio Italiano di Clinica Medica 1893. S. 356.

5) Dana, Acromegaly, gigantism, and facial Hemihypertrophie. Med. Record Vol. 44. New-York 1893. 
Einen Grund zu solchem Zweifel liefern die Berichte Hanaus ${ }^{1}$ ) über sechs Fälle von Hypophystumoren bei Akromegalischen, die er als parenchymatöse Strumen erkannte; ferner ein Fall von Mendel ${ }^{2}$ ) und einer von Comini ${ }^{3}$ ), die dann, durch Benda ${ }^{4}$ ) in einem Falle und durch Vassale (a. a. 0.) im andern, bei späterer histologischer Untersuchung als adenomatőse Struma der Hypophysis festgestellt wurden, während alle diese Tumoren früher für Sarkome gehalten worden waren.

Ich war bestrebt, in großen Zügen nur einige der hauptsächlichsten Ansichten über den Ursprung und die Pathogenese dieser interessanten Krankheit zusammenzufassen, und zwar diejenigen, welche bis zu einem gewissen Grade zu einer anatomischen Kontrolle geeignet sind. Es ist anzunehmen, daß mit Hinsicht auf die oben erwähnten Theorien nicht nur das aufmerksame Studium nener Fälle von Hypophysistumoren bei Akromegalischen nützlich sein dürfte, besonders wenn diese Tumoren in gewissen Einzelheiten sich von den bisher beschriebenen unterseheiden, sondern auch eine Mitteilung über jene Hypophysistumoren ohne Akromegalie ebensolches Interesse erwecken sollte, bei denen die histologische Untersuchung mit der größten Sorgfalt und den modernsten technischen Mitteln ausgeführt worden ist.

\section{Fall I.}

Hypophysistumor ohne Akromegalie.

Die Krankengeschichte dieses Falles sei hier nur in den hauptsächlichsten Umrissen angegeben; die kleine Kranke befand sich in der hiesigen Universitäts-Klinik.

Oliva Schiavon, 9 Jahre alt, geboren in Terranegra in der Provinz Padua, aus sehr armer Bauernfamilie stammend. Die Ernährung des Kindes war immer dürftig, trotzdem wuchs sie heran, ohne die gewöhnlichen Kinderkrankheiten durchzumachen, wenngleich sie schwäehlich und in ungenügendem Ernährungszustand war. Anomalien in ihren Gewohn-

1) Von Benda zitiert.

2) Mendel, Berliner klin. Wochenschr. 1900, S. 1031.

3) Comini, Arch. per le Scienze Mediche, Vol. XX, 1896.

4) Benda, Sitzungen d. Berliner Gesellsch. f. Psych. u. Nervenkrankheiten. 14. Januar 1901. 
heiten und Neigungen fielen nie auf. Mit Bezug auf pathologisehe Heredität ist nichts $\mathrm{zl}$ berichten.

Ihre ersten Krankheitserscheinungen fallen in den Februar 1902. Zu jener Zeit begann sie an Appetitlosigkeit, allgemeinen Schwächezuständen und Unwohlsein zu leiden, besonders an schweren, von häufigen" Diarrhoen begleiteten Leibschmerzen.

Hypophysistumor ohne Akromegalie (Fall Schiavon).

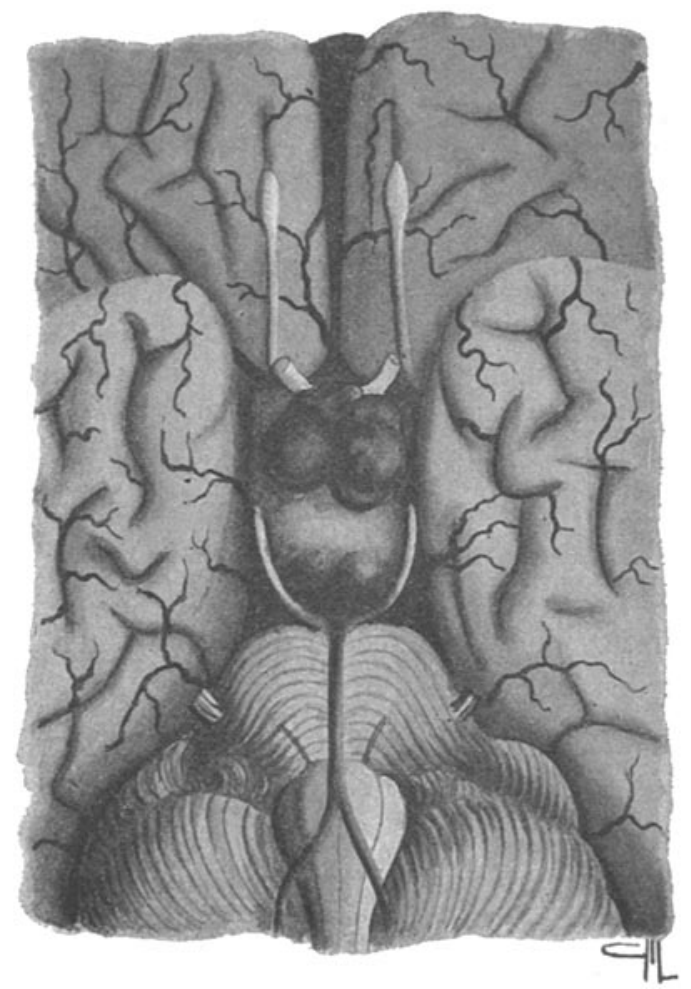

Fig. 1.

Der Tumor von der Gehirnbasis aus gesehen.

Die Entleerungen anfangs spärlich, breiig und von gelblicher Farbe. wurden bald reichlicher, flüssig, schleimig-serös. zuweilen auch blutig tingiert, und kamen in so kurzen Zwischenräumen, daß höchstens 3 Stunden. zwischen den eỉnzelnen Anfällen lagen ( $8-10$ in 24 Stunden). Sei es, $\mathrm{da} B$ die angewendeten Mittel oder die diätetische Behandlung besser anschlugen: die kleine Kranke besserte sich nach einem Monat zusehends, und die Besserung hielt in bezug auf die Darmstörungen an, trotzdem sich 
das Allgemeinbefinden verschlechterte, die Erschöpfung der Kräfte zunahm, sodaß der Charakter und das Aussehen des Kindes Zeichen eines sehr schweren Leidens erkennen ließen. So war auch der Eindruck, den die Ärzte Mitte April desselben Jahres hatten, als die kleine Patientin wegen beharrlicher and intensiver, auf die vordere Schädelhälfte beschränkter Kopfschmerzen gezwungen wurde, das Bürgerhospital, sodann die medizinische Universitätsklinik aufzusuchen.

Hypophysistumor ohne Akromegalie (Fall Schiavon).

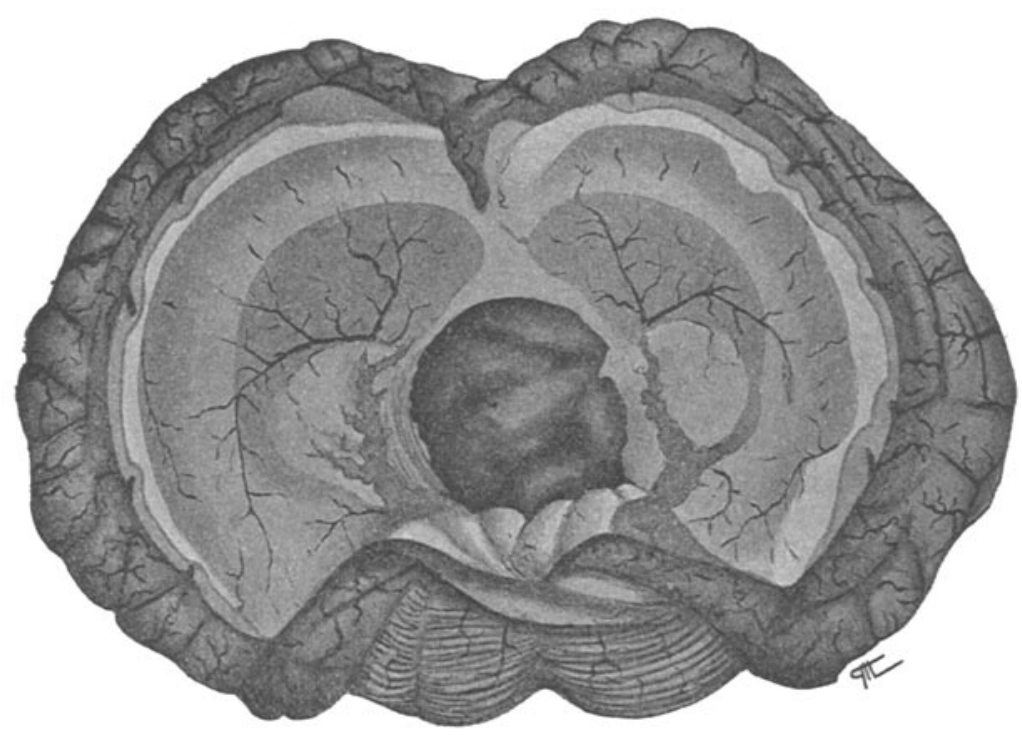

Fig. 2.

Der Tumor von der Höhlung des dritten Ventrikels aus.

Dort blieb sie 2 Monate, während welcher Zeit sie genau beobachtet und untersucht wurde. Selten zeigte die Patientin in dieser Zeit Temperatursteigerungen, und die beobachteten waren schnell vorübergehend und standen in Zusammenhang mit schweren nervösen Störungen, welche sie wenige Tage nach ihrer Aufnahme in die Klìnik betroffen hatten. Bei objektiver Untersuchung waren, neben dem schweren Marasmus und einer Herabsetzung des Denkvermögens, 'die schon allein den Verdacht einer intracramiellen Krankheit anfkommen ließ, Abweichungen in der motorischen Innervation bemerkt, besonders im Verzweigungsgebiet einiger Hirnnervenäste. Die Pupillen leicht erweitert, die Uvula etwas nach links abgewichen, beim Augenspiegeln Zeichen einer beiderseitigen Neuroretinitis, Im gegenseitigen Verhalten der optischen Achsen bei Bewegungen der

Virchows Archiv f. pathol. Anat. Bd. 176. Hft. 1. 
Bulbi keinerlei Anomalien. Von den Sehnemrefiexen der patellare stark gesteigert, von den Hautreflexen der plantare vollständig anfgehoben. Die Untersuchung der inneren Organe ergab nichts positives. Während der Aufnahme der objektiven Symptome bewegte sich die kleine Patientin stark gestikulierend im Bett, wie im Delirium, und beklagte sich über starke Stirnkopfschmerzen. Im Urin sehr niedriger Harnstoffgehalt $(3,07 \%$ \% im Kot sehr große Mengen von Ascaris lumbricoides-Fiern. Die Blutuntersuchung ergab folgende Zahlen: mit dem Fleis chlschen Hämometer 80 p. c. nach Ha y e 4160000 rote Blutkörperchen, mikroskopischer Befund negativ.

Der Aufenthalt der Patientin in der Klinik zog sich von Mitte April bis Mitte Juni hin, während dieser Zeit konnten die behandelnden Arzte einige interessante Befunde erheben. Besonders bemerkenswert war die enorme Polydipsie, welche an die der Diabetiker exinnerte, verbunden mit Anorexie und bisweilen auch mit plötzlichem Erbrechen, dem keine Ubelkeit vorausging, dem kein Gefühl relativen Wohlseins folgte, mit einem Wort: Exbrechen von cerebralem Typus. Schlaflosigkeit und fortwährende Unrwhe. Am Morgen des 27. April warde sie zum erstenmale von einem mit Verlust des BewuBtseins verbundenen Krampfantall betroffen, tonischklonische Kontraktionen der oberen und unteren Extremitäten waren damit verbunden, darauf folgte ein leichter Kollaps. Am selben Tage kam wenige Stunden später ein neuer Anfall mit analogen Kontraktionen, $\mathrm{Ab}$ weichung des Kopfes und der Augäpfel nach links, Verlust des BewuBtseins und der Sensibilität, Cyanose des Gesichts, Abgang von Urin. Solche Anfälle wiederholten sich dann während der Krankheit in vnregelmäßigen Zwischenräumen, ohne bestimnte Dauer, bald vorzugsweise anf der linken, bald auf der rechten Seite. Uber Sehstörungen klagte die Patientin in der Zeit zwischen den Anfällen nicht mehr, der Kopfschmerz und das Erbrechen wechselten in letzter Zeit sehr ihren Charakter. Die Kranke starb am 16. Juni, nachdem sie einige Tage vollständig bewubtlos gewesen war.

Die Sektion, 33 Stunden nach dem Tode ausgeführt, ergab folgenden Befund:

Leiche im Zustande starker Abmagerung, Haut sehr blaß, wachsartig, dünn. wenig elastisch. Subcutanes Gewebe und Muskeln im allgemeinen so atrophisch, daB die Skeletvorsprünge überall stark hervortraten. Im Gesicht keine Abnormitât, Lippen, Nase fein, Ohrläppchen sehr klein und platt, Stirn glatt, Stimhöcker wenig ausgeprägt, Jochbögen nur wegen der eingesunkenen Wangen hervortretend. Abdomen in der Leistengegend mit Fäulnisflecken bedeckt. Auf Hand- und FuBrücken, welche im Verhältnis zur Größe der Leiche normale Maße darboten, traten die Extensorensehnen wegen der ungewöhnlichen Magerkeit in ihrem ganzen Verlaufe stark hervor. Schädel sehr klein, dolichocephal, Sehädeldach dünn, mit spärlicher Diploe und leichten. Depressiones digitatae innen an den Seitenwandbeinen neben der Pfeilnaht. Dura mater etwas gespannt, transparent 
mit wenig hervortretenden Blutgefäßverästelungen. Sinus longitudinalis superior leer. Hirnwindungen an der Konvexität der Großhirnhemisphäre abgeplattet, besonders im Parietal- und Frontallappen; man hat den Eindruck, als ob eine Drucksteigerung von den tiefer gelegenen Hirnteilen ansginge, derart excentrisch, daß die Hemisphären gegen das Schädeldach stark angedrückt wurden. Infolge dessen findet sich in den Gefäßien der Pia nor sehr wenig Blut.

Bei Herausnahme des Gehirns bemerkt man beim Anheben der Frontallappen nach hinten, nachdem die Falx major von der Crista ethmoidalis abgeschnitten ist, daß die Nervi optici, dicht vor ihrem Eintritt in die Foramina optica abgeplattet sind und anf einer rötlichen, gelappten Masse liegen, welehe mit der Gehirnbasis zusammenhängt und sich gerade an der Sella tureica an dieselbe ansetzt. Nach Durchschneiden der Nervi optici, dicht an ihrem Eintritt in die Orbita, and Anheben der Hemisphären nach hinten, gelingt es nicht, den Tumor ganz frei zu bekommen, ein Teil desselben bleibt vielmehr fest an der Sella turcica hängen. Trotz anfmerksamster Untersnchung läßt sich an diesem Teile weder eine Spur von normalem Hypophysisgewebe, noch vom Operculum erkennen. Der innerhalb der Sella turcica liegende „intrasellare“ Teil der Geschwulst setze sich direkt vermittelst eines dicken Stieles in den "extrasellaren" oder ,interpeduncularen" Teil fort, weder in dem einen noch in dem anderen kann man Hypophysisgewebe finden. Wegen der veränderten Topographie des Gebietes bleibt der Befund ein in jeder Hinsicht schwer zu erklärender. Der extrasellare Teil des Tumors sitzt zwischen dem hinteren Winkel des Chiasma opticum und dem durch die Divergenz der Hirnstiele gebildeten Winkel, hat ungefähr die GröBe einer WalnuB, ist manlbeerförmig, tief rot, von markiger Konsistenz. Ein Lappen der Geschwulst reicht über das Chiasma hinüber bis an dessen vorderen Winkel, sodaß es nicht nur nach vorn gepreBt, sondern auch gegen den Teil des Orbitalrandes gedrückt wird, welcher die innere Seite des Trigonum olfactorium begrenzt. In der Querrichtung versehiebt die Neubildung die dem Keilbein aufliegenden Teile des Gehirns ein wenig, ohne jcdoch in sie einzudringen. Vom Circulus Willisii bleiben nur die Arteriae cerebri postcriores wohl erhalten, die anderen Äste sind so von Geschwulstgewebe gedrückt oder umgeben, daß sie weder auf noch neben dem Tumor zu erkennen sind. Letzterer ist von einer harten Kapsel bedeckt, die hier und da discontinuierlich die rote Farbe des Paremchyms durchscheinen läBt. Unter dieser dünnen Decke bemerkt man erweiterte, unregelmäßig netzförmig verlanfende Kapillaren. Die hinteren Lappen des Tumors hinter der Arteria cerebri posterior sind lebhaft gerötet und mit feinen Hämorrhagien dicht besetzt. Die Nervi oculomotorii verlanfen zur Seite der Neubildung und beschreiben gleich nach ihrem Ursprnng ein jeder einen weiten Bogen, indem sie den von dem Tumor eingenommenen Raum umfassen. Vom Tuber cinereum und den Corpora mammillaria findet sich keine Spur. Die Höhlen der Seitenventrikel sind sehr weit und enthalten 
eine seröse Flüssigkeit, die leicht rötlich tingiert ist, in reichlicher Menge. Das Ependym ist geschwollen, succulent, am Kopf der Nuclei caudati granuliert, die Ependymvenen sind geschlängelt und gefüllt. Nach Entfernung des Corpus callosum bemerkt man, daß der dritte Ventrikel von einer intensiv roten Masse vollständig gefüllt ist, welche schwammig anssieht, von kleinen Blutpunkten durchsetzt ist, die ungefähre GröBe eines halben Hühnereies hat, hemisphärisch ein wenig über die Höhe der Thalami optici hervorspringt. Diese Masse ist mit der oben beschriebenen, an der Basis sitzenden in direktem Zusammenhang, nur daß hier der Tumor seine Begrenzung verloren hat und die eigentliche Substanz der graßen Ganglien einnimmt, indem er ihre natïrliche Grenze gegen den dritten Ventrikel verändert. Die Corpora quadrigemina und die Glandula pinealis sind intakt. Die Plexus chorioides schwimmen in der in den Hinterhörnern reichlich angesammelten Flüssigkeit, sind blutreich und enthalten viele transparente Cysten. Die Blutpunkte in der weißen Substanz der Hemisphäre sind spärlich, das Aussehen der weiBen Substanz ist im ganzen anämisch und ödematös. Pons, Kleimhirn und Rückenmark bieten keine besonderen Veränderungen dar. Die Sella turcica zeigt sich nach Herausnehmen ihres Inhalts in allen ihren Dimensionen mäßig erweitert, der Knochen ist jedoch nirgends arrodiert; ebenso ist die Lamina quadrilatera des Keilbeines intakt. Der an der Dura mater am Grunde der Selle turcica adhärente Teil der Gesehwulst hat dasselbe Aussehen wie der zwischen den Pedunculi gelegene Teil: rosa, weich, schwammig, ganz verschieden von dem Bau einer normalen oder einfach hyperplastischen Hypophysis.

Auf einem Sagittalschnitt zeigt sich die Geschwulst einheitlich (rötlich sehwammig), nirgends sieht man eine Spur der bei normaler Hypophysis vorhandenen Zusammensetzung aus zwei Lappen.

Die Schilddrüse wiegt $16 \mathrm{gr}$, sie hat einen auf der rechten Seite gelegenen überzähligen, $3 \mathrm{~cm}$ langen Lappen, der bis an den hinteren Rand des Schildknorpels reicht. Auf einem Durchschnit sieht man die acinöse Struktar und die normale Farbe unverändert, das Gewebe ist dicht, man erkennt bei genauem Hinsehen ganz kleine Colloideysten als glänzende Punkte.

Bei. Untersuchung des Brustkorbes bemerkt man eine leichte Anschwellung rachitischen Charakters an den Rippenkn orpelansätzen. Das Herz liegt infolge Retraktion der vorderen Lungenränd er in gröBerer Ausdehnung frei, als normal. Pericard glatt und dünn, enthält nur wenig klare Flüssigkeit. Das Herz ist kontrahiert, auf der rechten Seite wenige Blutfiecke, Pericard, Endocard weithin getrübt, Herzmuskel atrophisch, blaß. Klappen, Aorten, Intima und Coronararterien ohne Besonderheiten, Lungen frei, voluminős, rosa, ohne Verwachsung mit der Brustwand und ohne parenchymatöse Verdichtung, Pleuren transparent und glatt. Auf dem. Durchschnitt nichts Besonderes.

Milz von normaler Größe mit glatter, dünner Kapsel, auf dem Durch- 
schnitt dunkelrot, an einigen am Rande liegenden Partien bläulich, Pulpa ziemlich reichlich, verdeckt das Bindegewebe und die Follikel. Arteria und Vena linialis normal. Nebennieren und Plexus coeliacus normal. An den Nieren ist nur ein gewisser Blutreichtum am Markkegel bemerkenswert. Die Untersuchung des Magen- nnd Darmtractus ergibt nichts pathologiseh Interessantes. Leber ziemlich klein, wiegt $390 \mathrm{gr}$, acinöse Zeichnung auf dem Durchschnitt wenig deutlich, Parenchym leicht braun, hie und da an der Kapsel einzelne versprengte anämische Zonen. An den tiefen Halsorganen nichts besonderes, außer einer leichten Vergrößerung der supraclavicularen Lymphknoten, analog der Veränderung der inguinalen, auf dem Durchsehnitt ließen sie eine markige Hyperplasie erkennen. Genitalorgan intakt.

Der Hypophysistumor und die Schilddrüsen wurden einer genauen histologischen Untersuchung unterzogen. Letztere, in Zenkerscher Flüssigkeit fixiert, mit Jodalkohol von den Sublimatniederschlägen befreit, wurde in Paraffin eingebettet. Stäcke der Geschwulst, and zwar vom intra- wie vom extrasellaren Teile derselben, kamen auf einige Tage in 10 p. c. Formol, wurden nach Merkel mit Chrom-Essigsäure gebeizt, sodann einer Chromsäurebehandlung steigender Konzentration $(0,5$ bis 1 p.c.) unterworfen, nach langem Auswaschen and Entwässern in Paraffin eingelegt. Für die Schilddrüse kamen die gewöhnlichen Färbungen zur Anwendung. Hämatoxylin-Eosin, Hämatoxylin-Saffranin mit folgender Differenzierung in Pikrin-Alkohol; sodann die van Gieson-Färbung. Zum Studium der Sekretgranula kam auch die von Benda empfohlene Färbemethode ${ }^{1}$ ) zur Anwendung, die Bruchstücke des Tumors wurden ansschließlich nach diesem besonderen Verfahren untersucht. Das aus der Sella turcica stammende Stüek wurde vollständig in Serien geschnitten, um zu sehen, ob irgendwelche Beziehungen zwischen dem Tumor und der Hypophysis beständen, in der Annahme, daß vielleicht Reste des Organs in erkennbarer Form zurückgeblieben sein könnten. Von den übrigen Tumorstïcken wurden einzelne Partien untersucht und zwar von der Peripherie und aus der Mitte des Gewebes, und besonders aus der Stelle, wo die Geschwulst die Wand des dritten Ventrikels berührte.

Der extrasellare Teil der Geschwulst zeigte bei schwacher Vergrößerung eine vollständige bindegewebige Umbüllung, die an einigen Stellen so dünn war, daß nur wenige der Oberfläche des Tumors parallele Fasern sich erkennen ließen, Diese mit wenigen Kapillaren versehene Membran schien keinen Anteil an dem eigentlichen Geschwulststroma zu haben, An den tieferen Geschwulstteilen, wo ein direkter Zusammenhang mit der Hirnsubstanz bestand, war eine eigentliche Kapsel nicht wahrzunehmen, wie schon die makroskopische Betrachtung vermuten lieB, nichtsdestoweniger bestand eine Begrenzungszone in der Weise, daß die Neuroglia mit Hyperplasie reagiert hatte. Das war, neben anderen feineren

1) Benda: Neurolog. Centralbl. 1900, S, 786. 
Strukturverhältnissen, ein Grund für das starke und rasche Wachsen der Geschwolst.

Das Geschwulstgewebe hatte in dem extraseilaren Teile iberall dieselbe Zusammensetzung. Eingebettet in ein sehr zartes Stroma mit unvollständigem Netzwerk, an einzeInen Stellen bestanden sogar nur sehr feinwandige Gefäße, liegt ein aus ziemlich voluminösen Elementen bestehendes Gewebe, eine Zelle dicht neben der anderen, höchstens durch ganz spärliche Intercellularsubstanz von einander getrennt. In der Anordning der Zellen bestand keine Regelmäßigkeit, anch ließen sich keine Beziehungen zu den benachbarten GefäBwandungen erkennen. An mehreren Stellen lagen zwar dickere Bindegewebszüge, im ganzen waren sie aber sehr spärlich. Wohl versehen mit spindelförmigen Kernen, hoben sie sich deutlich anf dem Gewebsgrunde durch ihre tiefrote Farbe ab, welche sie bei der Bendaschen Methode einer elektiven Affinität des Bindegewebes zum Sulfoalizarin verdankten, ihre Kerne erschienen nach derselben Methode blau. Im Innern dieses extrasellaren Teiles lagen Gewebszüge, in denen die neagebildeten Gefäße besondere Beziehungen angenommen hatten: sie enthielten um ihre ziemlich weiten Lumina braune Geschwulstelemente, welche durch Herde kleinzelliger Infiltration oder durch Blutungen nach außen hin verdrängt waren.

An solchen Stellen fanden sich kleine Haufen gelblicher Pigmentkömer zwischen den Zellen oder längs der Bindegewebsfasern, die Gefäße begleitend, anscheinend Zeichen alter Hämorrhagien. Die Weichheit der Neubildung and der Reichtum an Blutgefäßen in diesem Teile mußten günstige Bedingungen für Blutungen schaffen. Es fanden sich auch ganz frische Hämorrhagien, besonders in den tieferen Teilen der Geschwulst, da wo der Tumor in den dritten Ventrikel sich verwölbte, rote Blutkörperchen lagen da, ohne gerade Haufen zu bilden, einfach zwischen den Geschwulstzellen. Von diesem Reichtum an Blutgefäßen, und besonders von den reichlichen Hämorrhagien ist die hochrote, sehon oben erwähnte Farbe herzuleiten. Die den Tumor hauptsächlich bildenden Elemente, die Zellen, lagern in dem extrasellaren Teil der Geschwulst. regellos durcheinander, bald in Form von Haufen, bald wieder von einander durch telle Räume ohne eigene Wandung getrennt, an einigen. Stellen lag zwischen den einzelnen Zellen eine wenig färbbare, homogene, ganz fein granulierte Substanz. Die Zellen zeigten bei starker Vergrößerung einen beachtenswerten Polymorphismus: mit großen Kernen, die fast den ganzen Zellleib erfüllten, ließen sie nur ein spärliches Protoplasma erkennen, das oft nur aus einem feinen, den Kern ungebenden Saum bestand. Neben den zahlreichsten rumdlichen Zellen sah man spindelförmige. mit dickem Zellleib und zarten kurzen Polausläufern, dann etwas größere, polygonale, zweierlei Art, wie weiterhin beschrieben ist, mit reichlicherem Protoplasma, endlich birnförmige Zellen mit abgerundeter Spitze, kleinem Kern und spärlichem Protoplasma. Auch Riesenzellen mit $5-6$ Kernen fanden sich hin und wieder. Über die Art der Gruppierung dieser Ele- 
mente kann ich sagen, daß sie an denjenigen Stellen, wo Spindelzellen lagen, sich den Bindegewebsfasern anpaßten, indem sie mit ihren Längsachsen derart hintereinander lagen, daß die Poläusläufer der einen sich zwischen die Zelleiber zweier benachbarter hineinschoben. Zwischen diesen Zellen war nichts von einer Intercellularsubstanz wahrzunehmen, es resultierten daher Bilder wie beim Spindelzellensarkom. Solche Anordnung fand sich aber nur an einzelnen wenigen Stellen der Geschwulst. Sind schon alle Twmoren, die von der Sella turcica ausgehen, von groBem Interesse wegen der physiologischen Störungen, die sie erkennen lassen, so müssen etwaige Eigentümlichkeiten ihrer feineren Gewebsstruktur besonders hervorgehoben werden.

Die Zusammensetzung des Protoplasmas ist nicht in allen Zellen die gleiche, einige Zellen hatten klares Protoplasma, wenig lichtbrechend, glashell mit wenigen sehr feinen Granulationen, die entweder dicht am Rande oder neben dem Kern an dessen einem Pole lagen; bald liegt der Kern in einem vollständig hellen Zelleib, der sich erst an der Peripherie der Zelle verdichtet, in anderen Fällen sind die Granulationen gleichmäßig verteilt und geben dem ganzen Protoplasma einen starken und gleichmäßigen Glanz. Sie sind stets außerordentlich fein und lassen immer den stark gefärbten, scharf umrandeten Kern deutlich hervortreten (in den nach Benda gefärbten Präparaten). Solche Zellen fanden sich reichlich in allen Teilen der Geschwulst, ihr Kern erschien im Gegensatz zu dem spärlichen Protoplasma groß und wie gebläht. Es fanden sich anch Zellen mit homogenem, scharf begrenztem Protoplasma, ferner kleine Klumpen ganz homogenen Protoplasmas ohne Kern mit unscharfen Rändern. In den Riesenzellen war nicht nur die Zahl der Kerne größer, sondern auch die Masse des Protoplasmas reichlicher als in den ein- oder zweikernigen Zellen; in allen Zellen jedoch, anch bei den feinstgranulierten, zeigte sich das Protoplasma nach der Bendaschen Methode in höherem oder geringerem Grade dunkelrosa gefärbt. Zellen, die man nach Form, elektiver Färbung und Reichtum und Größe der Granula mit den normalen chromophilen Zellen der Hypophysis anch nur entfernt hätte vergleichen können, fanden sich ganz und gar nicht hier vor.

Lebhaft mit Toluidinblau gefärbt waren im Gegensatz zum Protoplasma die Granula- und die Chromatinfäden der Kerne. Solche Kerne lagen gewöhnlich in der Mitte des Zellleibes, allein oder zu zweien, auch zu vieren und mehr in den Riesenzellen: sie waren sehr groß, rundlich, wenn einzeln; nierenförmig, wenn sie zu zweien lagen, von ganz verschiedener Form in den Riesenzellen. Bei den ruhenden Kernen bestand ein sehr scharfer Kontur und hob sich scharf vom rosa Protoplasmagrund ab, manchmal wie ein tiefblauer, fast schwarzer Kreis: das Chromatin des Kerns war nämlich gegen die Peripherie hingezogen, sodaß im Zentrum nur wenig davon zu erkennen war. Solche Bilder erregten die Vorstellung einer "Wandhyperchromatose", wie sie als pathologische Kernform von Schmaus und Albrecht und von Coulon beschrieben ist; in unserem 
Falle war das Zentrum der Kerne jedoch fast nie ganz von Granula entblöBt. Ich habe bierbei an meinen Präparaten klare Bilder über die Verteilung der Chromatinstäbchen und Granula im Innern der Kerne erhalten. Die Granula waren bisweilen alle gleich grob, - rundlich, blau gefärbt und mit einer gewissen Regelmäßigkeit im homogenen Karyoplasma verteilt und lagen in ungefähr gleichen Abständen von einander; Chromatinanhänfungen als Kernkörperchen konnten nirgends gesehen werden. In anderen Kernen dagegen hatte sich ohne Andeutungen von Karyokinesen das Chromatin in zwei oder drei gröBere Klumpen zusammengezogen, die gewöhnlich rundlich waren, scheinbar Kernkörperchen darstellten, die zwisehen den Granula nnd feinen Fäden hier und da im Karyoplasma verstreut lagen. Homogene Kerne entdeckte ich in keinem Teil der Gesehwulst, alle hatten mehr oder weniger deutlich erkennbare Granula, die am besten nach der Bend a schen Miethode dargestellt wurden. Kernteilungsfiguren waren zablreich vorhanden: Spindeln, Äquatorialplatten, Monaster etc., die Zellen mit Kernteilung waren größer und hatten helleres Protoplasma als die im Ruhezustand. Zellen mit direkter Kernteilung oder Kernsprossung konnte ich nirgends finden, ich halte die Vielkernigkeit der Zellen für den Ausdruck eines endogenen, nicht mit Protoplasmateilung verbundenen Vorganges, sodaß daraus die oft beträchtlichen Kernhaufen innerhalb ein und desselben Zellleibes resultieren.

Rundliche, nach Art von Vakuolen auftretende Löcher, wie man sie im Innern des Zellleibes sonst bei rasch wachsenden Geschwiulsten oft findet, waren bei diesem Tumor nirgends $\mathrm{zu}$ sehen, dagegen lagen oft, besonders in den der Gehirnsnbstanz näherliegenden Teilen des Tumors innerhalb der Geschwulstzellen kleine gelbliche Körner, die stark das Licht brachen, denjenigen ähnlich, die, wie ich vorher beschrieben habe, dicht neben den Wandungen der nengebildeten GefäBe und zwisehen den die Gefäße begleitenden Bindegewebszügen lagen. Derartige Pigmentkörner von unzweifelhaft hämatogenem Ursprung zogen die Peripherie des Zellleibes vor, sie waren stets ziemlich spärlich.

In den dem dritten Ventrikel mehr benachbarten Teilen der Geschwulst fehlte dieser eine seharfe Grenze gegen die großen Ganglien der Gehimbasis, nur hatten sich an diesen Stellen die Endothelkerne der Lymphräume, die kaum vom Tumor ergriffen waren, vermehrt, lagen dicht aneinander, sodaß sie gleichsam einen feinen Saum bildeten, der das neugebildete Gewebe vou der Gehirnsubstanz trennte; solehe reaktiven Proliferationen veranlaßten ein Hervorwachsen wahrer Protoplasmaknospen, in welchen auf einex amorphen, nach Bend a rosa gefärbten Grundsubstanz zahlreiche blaue, runde, haufenweise liegende Kerne hervorschossen.

Die der Geschwulst benachbarte Gehirnsubstanz verhielt sich sozusagen passiv gegenüber der Neubildung, welche stufenweise sie vordrängend, vorrückte; nur in einer engbegrenzten Zone fanden sich Spuren einer Neuroglia-Hyperplasie, ihre etwas dickeren und vermehrten Fibrillen bildeten ein feines, zartes Flechtwerk, bloß von dem der Geschwulst un- 
mittelbar anliegenden Teile nervöser Substanz umgeben. Hier fanden sich anch die Kerne der Glia zahlreicher als an den anderen Orten längs der Begrenzungslinie.

Die Nervenzellen zeigten in der Nachbarschaft der Gesehwulst schwere mechanische und Ernährungsstörungen infolge der durch den Tumor ausgeübten Kompression: homogenes Aussehen mit schlecht erkennbaren chromatophilen Massen, einem aufgeblahten, nach Benda sich schlecht blaufärbendem Kern, an Zahl und Größe reduzierte, kurze Protoplasmaausläufer, Vakuolenbildung im Protoplasma. Etwas nervöses Gewebe bestand auch zwischen den Gewebsmassen an dem Teile, der am dritten Ventrikel lag, die dort vorhandenen Nervenzellen waren auf die Hälite bis auf den dritten Teil der normalen Größe verkleinert. Auch einzelne Gliafasern waren innerhalb des Tumors hier und da zu bemerken, als cylindrisch gewundene Bälkchen von tiefblaner Farbe, zwei bis dreimal so dick wie normale Gliafasern, an den Enden scharf abgeschnitten und ziemlich lang.

Viel interessanter gestaltete sich die Untersuchung des intrasellaren Teiles der Geschwulst, insofern, als ich in Serienschnitten durch den ganzen Inhalt der Sella turcica Reste von Hypophysisgewebe nachweisen and die Beziehungen zwischen diesen Resten und dem Tumor bestimmen konnte.

Auf einem Sagittalschnitt durch den intrasellaren Teil der Geschwulst ließen sich zwei Zonen deutlich voneinander abgrenzen. Von diesen unterschied sich die obere, die fast die ganze Höhlung, der Sella turcica einnahm, in nichts von dem Geschwulstgewebe: wir finden da die gewöhnlichen großen rundlichen Zellon vorherrschend, mit großen Kernen, in regelloser Lage, dicht nebeneinander innerhalb einer spärlichen, homogen erscheinenden Intercellularsubstanz. Hin und wieder befand sich auch ein zartes Stroma zwischen den Zellen, das aus sehr feinen Bindegewebsfibrillen und wenigen dünnwandigen, stark gefïllten Blutgefäßen bestand. Dieser oben gelegene Teil nahm ungefähr vier Fünftel vom Inhalt der Sella tureica ein, hatte ein deutliches Geschwulstgepräge und setzte sich nach unten gegen eine dünne, blattförmige, ungefähr $1 \mathrm{~mm}$ dicke Leiste ab, die von dem Tumor gegen den Boden der Sella tureica gepreßt zu sein schien und sich demselben anschmiegte. Dieser Gewebsstreifen hat ein entschieden drüsenförmiges Aussehen und wird von dem darüberliegenden Tumor durch ein kräftiges Bindegewebsbündel getrennt; die erwähntén Beziehungen finden sich in einer großen Zahl der Serienschnitte. Die drüsige Partie wird von einem bindegewebigen Stroma gebildet, welches, netzförmig angeordnet, längliche, am Grunde der Sella mehr rundliche Maschen bildet, die sogar zu wahren Spalten an einigen Stellen zusammengepreßt erscheinen. In diesen Maschen liegen zarte Zellen, die, kleiner als die des Tumors, rundlich, einen schlecht färbbaren Kern von runder Form enthalten und ein helles homogenes Protoplasma anfweisen. Nach der Bendaschen Methode nimmt der Kern eine blaß- 
blane, gleichmäßige Färbung an, das Protoplasma dagegen eine mehr nach rosa als nach blau hinneigende. Diese Zellen liegen dem bindegewebigen Stroma, das Alveolen bildet, auf und lassen in ihrer Mitte einen kleinen, mit körnigem Detritus und kleinen Colloidklumpen gefülten Raum frei. Zellen, die den normalen des Vorderlappens der Hypophysis gleichen und sich mit Alizarinblau tiefblan färben, gab es hier nicht. Mit wässeriger Eosinlösung färbte sich das Protoplasma bei längerer Behandlung diffus rosa, ohne dab eosinophile Granulationen zu erkennen gewesen wären. Es fehlten also vollständig die beiden Varietäten der chromophilen Zellen, sowohl die basophilen als die acidophilen, welche sich nach der Schönemannsehen Finteilung in einer normalen Hypophysis immer finden. Die letzteren dieser schlecht zu färbenden Zellen sind scharf, und oft liegen sie aufgelöst im Centrum des Alveolus in kleinen, von Kernen durchsetzten Protoplasmahaufen nach Art der von Rogowitseh1) als "Kernhaufen" beschriebenen Bijdungen, die sich an der Grenze des nervösen and epithelialen Teiles der Hypophysis vorfinden. Wenn man in den besser erhaltenen Elementen dieses drüsigen Abschnittes die Verhältnisse des Protoplasmas und der Kerne mit starker VergröBerung untersucht, so findet man, daß sie von denen der Tumorzellen vollständig verschieden sind: hier ist der Kern klein und von einem, in anbetracht der Kleinheit der Zelle, relativ großen Protoplasmamantel umgeben, im Gegensatz zu den oben beschriebenen Tumorzellen, wo der relativ große Kern einen nur schmalen Protoplasmasanm um sich herum hat.

An dem Knotenpunkte des Stromas bemerkt man reichlich BlutkapilJaren, die an die Wand der Alveolen durch den Tumor angepreßt und plattgedrückt waren; in ihrem Lumen befinden sich rote Blutkörperchen in geringer Menge.

Thyreoidea: Schnitte aus diesem Organ wurden nach den gewöhnlichen Methoden, auRerdem nach der schon erwähnten neuen Bendaschen gefärbt. Das Parenchym zeigte ziemlich reichen Colloidgehalt, wenigstens die Cysten im Zentrum, während die an der Peripherie ziemlich weit und out konfluiert waren. Auf der inneren Oberfläche einer jeden Cyste Iagen in einfacher kontinuierlicher Lage Epithelzellen; selten finden sich Sehläuche, bei denen sich die Epithelien mit dem Colloid im Zentrum des Lumens mischen. Auch an den peripherischen Abschnitten der Drüse sieht man nur ansnahmsweise Stellen, an denen sich Epithelzüge über die Fasern des Stromas hinausbegeben, um neue Alveolen zu bilden, wie man es an hypoplastischen Schilddrüsen wahrnehmen kann.

Mit stärkerer VergröBerung suchte man vergebens in mehreren Gesichtsfeldern von mit Saffranin und Pikrinsäure oder nach Benda gefärbten Präparaten nach Kernteilungsfiguren, auch konnte man in ähnlicher Weise keine Differenz zwischen zwei Arten von Zellen erkennen, wie sie Langendorf $\mathrm{f}^{2}$ ) aufgestellt hatte: Hauptzellen und Colloidzellen. Alle

1) Rogowits ch: Zieglers Beiträge, Bd. IV, 1889.

2) Langendorff: du Bois-Reymonds Archiv, Supplement 1889. 
Zellen zeigten ohne Untersehied dieselben Charaktere: einen ziemlich großen Kern von runder Form, reich an Chromatin, mit spärlichem Protoplasma von homogenem Aussehen. Das Bindegewebe, welches die Drüse zusammenhielt, ist gut entwickelt, die Septen zwischen den Epithelschläuchen sind ziemlich voluminös und arm an Blutgefäßen. Einige stärkere Bindegewebszüge nehmen mit Eosin und Sulfo-Alizarin eine gleichmäßige rosa Farbe an und sind spärlich mit länglichen Kernen versehen, in ihnen ist eine starke hyaline Degeneration vorhanden.

Verschiedene der über den Tumor hypophyseos bei nicht akromegalischen Individuen noch in letzter Zeit erschienenen Beobachtungen können nicht dazu beitragen, über die Frage der Beziehungen der Hypophysis zur Akromegalie Licht zu verbreiten, und zwar aus einem Hauptgrund: weil die histologische Untersuchung; wegen des unterlassenen Studiums der zwischen Hypophysis und Tumor bestehenden Verhältnisse, unvollkommen erscheint. Beinahe alle Beobachter beschränken sich darauf, nach dem makroskopischen Examen zu versichern, daß "keine Uberbleibsel des Hirnanhangs vorhanden sind", als ob es eine leichte Sache wäre, sich über das Vorhandensein solcher Reste oder das Fehlen derselben ohne weiteres auszusprechen. nachdem es bekannt ist (Benda), daß die Hypophysis nach den verschiedensten Richtungen gedrängt werden kann, je nach dem Ausgangspunkt und der Wachstumsrichtung des Tumors, Das schwammige Aussehen, das die Tumoren des Türkensattels in einigen Fällen zeigen, und die im neoplastischen Gewebe und in den benachbarten Teilen häufigen Blutergüsse, machen die Untersuchung so ungewiß und schwierig, daß man an der Richtigkeit der mit bloßem Auge vorgenommenen Betrachtung zu zweifeln berechtigt ist. Ebenso sind die histologischen Berichte über die verschiedenen Fälle mangelhaft, denn die Untersuchung ist fast immer auf ein Stückchen des Tumors beschränkt, und es ist selten, daß der Beobachter es für nötig hält, nachzuforschen, wie sich die Neubildung hinsichtlich des normalen Inhalts der Sella turcica verhält. Deswegen glaube ich, daß man nicht selten der Hypophysis einen ganz anderen Anteil im Krankheitsprozeß zuschreibt, als ihr zukommt, und daß man auf Grund der groben topographischen Anhaltspunkte solche Tumoren von der Hypophysis ausgehend ansieht, welche im Gegenteil in ihrer Nachbarschaft (Knochenwände, Infundibulum, 
Operculum Sellae turcicae) den Ursprung haben und die Drüse nur indirekt in Mitleidenschaft ziehen.

Es ist weniger meinem Verdienst, als glücklichen Umständen zuzuschreiben, daß ich über den ersten Fall einen histologischen Befund liefern konnte, der mit Rücksicht auf das Vorerwähnte keine Lücken aufweist.

Während man bei makroskopischer Untersuchung auch in diesem Falle auf das völlige Fehlen der Drüse schließen mußte, hat eine systematische histologische Untersuchung des Inhalts des Türkensattels die vom Tumor gegen den Hintergrund der Sella gequetschte Hypophysis erkennen lassen, welehe durch eine Bindegewebsschicht vom Tumor getrennt war. Ein glücklicher Zufall erlaubte das Auffinden gerade des interessantesten Teiles, nämlich des Vorderlappens, während der Hinterlappen und Stiel vollständig fehlten. Jener war in vertikaler Richtung und der Wölbung der Sella folgend, zu einer ungefähr $1 \mathrm{~mm}$ starken und in der Mitte etwas dickeren Schicht, also zu einem Sechstel des Normalen, zusammengedrückt; natürlich waren große Veränderungen in seinen Bestandteilen, im Epithel, Bindegewebe und in den Blutgefäßen wahrnehmbar. Die sonst runden Alveolen waren ellipsen- und maschenförmig verändert und an einigen Stellen zu dünnen Spalten geformt. Sie enthielten im Lumen wenige rundliche oder polygonale Zellen, welche, nicht immer ausgeprägte Konturen besitzend, von der Größe eines Leukocyten waren, und ein helles, von Granula ganz freies Protoplasma mit gleichmäßig färbbarem Kern zeigten. Da und dort fanden sich kleine Schläuche, die mit einer einfachen Epithelschicht ausgekleidet waren und in der Mitte ein sehr kleines Colloidklümpchen enthielten. An den Knotenpunkten des Bindegewebsnetzes waren zahlreicheBlutgefäße mit sehr engem Lumen. Die Struktur des Vorderlappens war also gut erkennbar, trotz der schweren, dureh den Druck erlittenen Atrophie.

Für ein besonders wichtiges Zeichen halte ich das gänzliche Fehlen der Chromophilzellen, was zugunsten von Bendas Hypothese spricht, nach welcher diese das funktionierende Element der Hypophysis darstellen; es ist natürlich, daß die der Zerstörung entgangenen Zellen des Hypophysisgewebes, bei einer so schweren Ernährungsstörung, neben der auffallendsten äuße- 
ren Schädigung (Form, Größe, Färbbarkeit) anch in ihrer Funktion die Wirkung dieses abnormen Zustandes fühlten, selbst wenn diese nur die Folge eines einfachen mechanischen Einflusses war. Hier ist das Fehlen der granulierten Zellen noch viel bezeichnender, insofern als in der Hypophysis von jungen Individuen, wie gerade im vorliegenden Falle, die Chromophilzellen gewöhnlich die Hauptzellen an Zahl übertreffen.

Der Umstand, daß anch die Colloidklümpehen sehr spärlich vorkommen, zeigt, meiner Meinung nach, ein unbestreitbares Verhältnis zwischen der Anzahl der Chromophilzellen und der Bildung der Colloidsubstanz. Dieser an Hypophysisresten von so anomalem Aussehen und Ernährung gemachte Befund genügt nicht nur, ohne weiteres die Meinung Bendas ${ }^{1}$ ) zu verwerfen, daß das Colloid nicht ein Sekretionsprodukt der Hypophysis darstellt, sondern nur ein Degenerationsprodukt. Um diese Frage zu lösen, sind eingehende systematisehe Untersuchungen der gesunden Hypophysis in verschiedenem Alter nötig, und ich hoffe, diese mit dem schon von mir gesammelten reichen Beobachtungsmaterial ausführen zu können. Um die erwähnte Beziehung zwischen Chromophilzellen und Colloidsubstanz zu bestätigen, könnten, wenn ich nicht irre, die Befunde von Benda selbst angeführt werden, welcher im Falle Köhler Colloidklumpen in den an Chromophilzellen reichen Stellen des adenomatösen Struma beschreibt, und ferner außer meinem auch der Befund von Carbone, der in seinem Falle von adenomatöser Struma der Hypophysis das Fehlen der Chromophilzellen und gleichfalls des Colloids erwähnt. Ich verdanke Herrn Professor Carbone die Möglichkeit, viele Schnitte des von ihm beschriebenen Tumors untersucht zu haben, ohne jemals in den Alveolen oder in den Lymphräumen Colloidsekret bemerken zu können. Diese Ergebnisse lassen auf eine mit Bendas Ansichten nicht übereinstimmende Beziehung zwischen diesen beiden Bestandteilen der Hypophysis schließen.

Abgesehen von diesen Einzelheiten, die eine rein morphologisehe Bedeutung besäßen, wenn sie sich nicht mit der noch unbekannten Funktion der Hypophysis verbänden, genügt es,

1) Benda, Verhandl. d. physiol. Gesellsch. zu Berlin, 1900, S. 166. 
nur die Beziehungen zwischen Hypophysisresten und Tumor und den großen, zwischen Hypophysiszellen und Tumorzellen bestehenden Unterschied hervorgehoben zu haben. Der Kern der Frage liegt darin, zu beweisen, daß es sich in meinem Falle um einen nicht aus dem Hypophysisepithel entstandenen Tumor handelt, der mit der sog. adenomatösen, mit Chromophilzellen besetzten Struma nichts gemein hat, was einige Autoren für die Ursache der Akromegalie halten. Daß keine Struma hier vorliegt, zeigen die folgenden Merkmale: die durch ein Bindegewebsblättchen zwischen Hypophysisresten und Tumor bestehende Abgrenzung, die Form, die Zusammensetzung und die gegenseitige Stellung, sowie die verschiedene Färbbarkeit der Zellen in beiden Geweben, auch an den Berührungsstellen, wo Ubergangsformen zwischen Drüsen- und neoplastischen Zellen gefunden werden müßten. An diesen Punkten zeigt sich keine Neigung des neoplastischen Gewebes zu einer alveolaren Anlage, sondern ein unvermitteltes Übergehen der kleinen, atrophischen, ungefärbten Zellen der Drüsenreste zu den großen, mehrkernigen, gut färbbaren Tumorzellen.

Das verschiedene Aussehen und die Gruppierung der neugebildeten Zellen, sowie der Reichtum an Blutgefäßen und die ausgesprochene Neigung zu Blutungen, bestimmen mich, diesen Tumor mit aller Sicherheit in die Kategorie der polymorphen, teleangiektatischen Sarkome zu setzen. Welches die wahre Ursprungsstelle des Tumors ist, kann nur sehr schwer beurteilt werden, wenn man bedenkt, daß er wegen seiner Größe und seiner starken Wucherung die umliegenden weichen Teile in Mitleidenschaft gezogen und teilweise zerstört hatte, wodurch eine genane Direktive der Untersuchung ausgeschlossen wurde. Sein Ursprung von den Knochen der Schädelbasis, die sich alle unverletzt zeigten, scheint nicht annehmbar, ebensowenig von der Dura mater, deren Tumoren gewöhnlich charakteristische histologische und, wenn man will, auch makroskopische Merkmale besitzen, die von dem vorliegenden Tumor gänzlich verschieden sind. Keine größere Wahrscheinlichkeit hat die Annahme des Ursprungs des Tumors aus den Endothelial- und Perithelialzellen der Gefäße. Tatsächlich habe ich nie im Innern der Blutgefaßie die Endothelialzellen vermehrt gesehen; 
auch in den größten GefäBen bestand der Epithelbelag aus abgeplatteten, in einer einzigen Schicht gelagerten Zellen. Ebenso bestand auch keine nähere Beziehung zwischen den Tumorzellen und der Adventitia der Gefäße, und es fehlte auch jene besondere strangförmige, radial von der Gefäßperipherie ausgehende Anordnung der Zellen, die man für ein charakteristisches Merkmal von Perithelialgesehwülsten hältt ${ }^{1}$ ).

Da man weder vom Hinterlappen, noch vom Trichter des Hirnanhangs Spuren finden konnte, läßt sich möglicherweise der Schluß ziehen, daß vielleicht einer dieser zwei integrierenden Bestandteile des Organs den Ausgangspunkt des Tumors darstellen könnte. Solche Fälle finden sich schon in der Literatur angeführt; was den Hinterlappen als Ursprungsstelle betrifft, erinnere jeh an den Befund von $\mathrm{Bury}^{2}$ ), welcher über ein von dem hinteren Teil der Hypophysis ausgehendes Gliom berichtet, und ferner an den zweiten Fall von Dallemagne (a. a. 0.), wo die Volumzunahme der Hypophysis ganz auf Rechnung des Hinterlappens vor sich ging.

Vielleicht hatte auch der von Mossé und Daunic ${ }^{3}$ ) beschriebene Fall von spindelzelligem Gliosarkom denselben Ursprung. Ein Fall von aus dem Trichter des Hirnanhangs entspringendem Tumor wurde kürzlich von Touche $\mathrm{e}^{4}$ ) mitgeteilt.

Ich bin geneigt, anzunehmen, daß auch in meinem Falle der Tumox vom Trichter des Hirnanhangs ausgegangen ist, obwohl bei der Nähe des Hinterlappens zum Trichter und der Größe des Tumors ein sicherer Anhaltspunkt fehlt; immerhin könnte ich zur Unterstützung meiner Auffassung einige Umstände ins Treffen fübren: vor allem das nach oben überwiegende Wachstum des Tumors, so daß der davon in der Sella turcica befindliche Teil, wenngleich er den Hinterlappen wegen seiner engen Nachbarschaft mit dem Trichter zerstören konnte, doch den Vordexlappen wohl zusammenzudrücken, aber nicht zu zerstören im stande war. Unmittelbar oberhalb des Türken-

1) Borst, Die Lehre von den Gesehwülsten. Bd. II, 1902.

2) Bury, British Medical Journal Bd. I, S. 1179, 1891.

3) Mossé et Dannic, Bulletins de la Société anatomique de Paris 1908. Fascic. 16, pag. 633.

4) Touche, Bull. de la Boc. anat. de Paris 1902. S. 217. 
sattels hatte der Tumor das Aussehen einer großen höckerigen Masse, die mehr gegen die Höhle des dritten Ventrikels vortrat, als gegen den Türkensattel.

Auf Grund des von dem an der Grenze zwischen Nervensubstanz und Tumor liegenden Gewebe gezeigten Charakters konnte man sicher nicht glauben, dab es sich um eine von der dritten Ventrikelwand ausgehende Neubildung handle. Es existierte tatsächlich kein Obergang von einem zum andern Gewebe, ja. es bestand sogar eine scharfe Abgrenzung infolge der leichten Zunahme der Neuroglia.

Obwohl man mit Wahrseheinlichkeit den Ursprung dieses Tumors vom Trichter des Hirnanhangs annehmen kann, bleibt es doch immer nur eine Hypothese.

Es liegt mir hauptsächlich daran, die Bedeutung hervorzuheben, welche die vorliegende Beobachtung in Hinsicht auf die Frage der zwischen Hypophysisfunktion und Akromegalie angenommenen Beziehungen besitzt. Wegen der indirekten Wichtigkeit, die diesem Falle in Bezug auf die sog. "Hypophysistheorie" zukommt, kann er in die Kategorie der von Weigert ${ }^{1}$ ), Barbacei ${ }^{2}$ ), Sokoloff ${ }^{3}$ ) und Schmidt ${ }^{4}$ ) beschriebenen gesetzt werden. Obwohl die Beobachtungen dieser Autoren eine von meinem Falle verschiedene Erkrankung der Hypophysis festgestellt hatten, da es sich in den drei ersten Fällen um ein syphylitisches Granulom and im letzten um einen schon käseartig entarteten Tuberkel handelte, waren die Folgen für das Organ überall den von mir beobachteten gleich: nämlich ein groBer Teil des Vorderlappens war zerstört, wie z. B. im Falle von Sokoloff: „von dem Gewebe der normalen Hypophysis waren kaum einige Alveolen mit Epithelzellen in der Peripherie des Tumors zu erkennen", gerade so wie in meinem Falle. Hier aber tritt noch ein Moment hervor, das ihm mit Bezug auf histologisches Detail ein noch viel größeres Interesse verleiht, nämlich der gänzliche Mangel an Chromophilzellen in den Uberbleibseln der Hypophysis, welchen

1) Weigert, Dieses Archiv Bd. 65, S. 223.

2) Barbacci, Lo Sperimentale, 1891.

3) Sokoloff, Dieses Archiv Bd. 143, S. 333.

4) Schmidt, Ergebnisse d. allg. Pathol. von Lubarsch u. Ostertag. 
Befund ich wegen der diesen Elementen gegenwärtig zugeschriebenen Bedeutung noch besonders hervorheben möchte.

Diese Beobachtung steht mit der Ansicht der französischen Schule nicht direkt im Widerspruch, welche, wie gesagt, die Akromegalie durch eine Verminderung oder durch Aufhören der Hypophysisfunktion hervorgerufen ansieht, weil man, trotz des Fehlens der Chromophilzellen, eine mögliche, wenn auch noch so geringe Funktion den übrig gebliebenen Resten dieses Drüsengewebes nicht absprechen kann. Man muß jedoch gestehen, daß es überraschend ist, warum, hinsichtlich der diesem Organ zugeteilten so wichtigen physiologischen Aufgabe, nämlich das Wachstum des Knochensystems zu regulieren (Tamburini, Pechkranz, Collina) nach Konstatierung einer so sehweren Sehädigung seiner Struktur und indirekt seiner Funktion wie in meinem Falle, nicht wenigstens die Andeutung von jener Knochenveränderung von mir gefunden wurde, welche für die Folge einer mangelhaften Hypophysisfunktion gehalten wird; aus diesem Grunde gerade müßte mein Befund mehr gegen als zu Gunsten dieser Anschanung spreehen. Gänzlich im Widerspruch steht er mit der Auffassung von Collina ${ }^{1}$ ), der die Meinung ausspricht, der Hypophysistumor veranlaßte bei einem jungen akromegalische und bei einem erwachsenen Patienten kachektische Erscheinungen, obgleich in beiden Fällen ein Aufhören der Hypophysisfunktion im Spiele ist. Denn einen anderen Fall von Hypophysistumor, der wegen des zarten Alters des von ihm befallenen Individuums besser gegen die Hypothese von Collina spricht als der meine, kenne ich nicht. Hier lag ein sehr auffallender allgemeiner Hypotrophismus vor, den man ohne weiteres einem rasch wachsenden Tumor in der Schädelhöhle zuschreiben muß, ohne daß das Organ, von dem der Tumor ausgeht, hierbei eine Rolle spielt. Sicher ist, daß in diesem Falle alle jene Symptome (Fettleibigkeit, Myxödem) fehlten, welche nach Fröhlich ${ }^{2}$ ) bei Nichtexistenz von Akromegalie einen Hypophysistumor anzeigen können.

Zur genauen histologischen Bearbeitung meines Falles habe

1) Collina, Rivista sperimentale di Freniatria e Med. legale, 1898, Fase. III.

2) Fröhlich, Wiener klin. Rundschan, 1901, 47, 48.

Virchows Archiv f. pathol, Anat. Bd. 176. Hft. 1. 
ich für angezeigt gehalten, die Untersuchung auch auf die Schilddrüse auszudehnen, da es bekannt ist, daß man seit langem eine hypothetische, kompensierende Funktion zwischen dieser und dem Hirnanhang annimmt. Diese gegenseitige Funktion beider Organe, zuerst von Rogowitsch (a. a. O.) angenommen, der bei Tieren nach der Schilddrüsenexstirpation eine Vergrößerung der Hypophysis konstatierte, ist in verschiedener Art beurteilt worden, und noch hente findet diese Ansicht auf Grundlage chemisch-physiologischer Daten ihre Verteidiger ${ }^{1}$ ) oder ihre auf höchst wertvolle Beweisführung sich stützenden Gegner [Vassale $\left.\left.{ }^{2}\right)\right]$. Die ersteren besitzen ein unbestreitbar reichliches Untersuchungsmaterial: es liegen Fälle vor, wie die schon erwäbnten von Rogowitsch und die späteren von Tizzoni und Centanni ${ }^{3}$ ) und von Leonhardt ${ }^{4}$ ), wo die Hypophysis nach der Schilddrüsenexstirpation sich vergrößert und gleichfalls andere, rein anatomische Fälle - weil die zu experimentellen Zwecken vollzogene Zerstörung der Hypophysis keine sicheren bezüglichen Schlüsse zuläßt - in denen das spontane Sehrumpfen und die Atrophie der Hypophysis von Sehilddrüsenhyperplasie begleitet ist. Was diesen letzteren Befund betrifft, gegen den, wie mir scheint, mein Fall spricht, so sei mir die Bemerkung gestattet, daß das Gewicht der Schilddrüse (auf welches viele ihre Ansicht stitzen) kein bestimmtes Urteil bezüglich der kompensierenden Hypertrophie des Organs zuläßt, wie das die Untersuchungen Schönemanns (a.a. 0.) beweisen. In der Statistik von Schönemann (a. a. O. Seite 323-324) sehen wir verschiedenem Alter beinahe dasselbe Gewicht der Schilddrüse entsprechen (7 Jahre $11 \mathrm{~g}, 30$ Jahre $13,5 \mathrm{~g}$ ) und in einigen von mir an 117 Kadavern ausgeführten systematischen Untersuchungen finde ich bei vier Fällen ein umgekehrtes Verhältnis, d. h. bei demselben Alter ein verschiedenes

1) Eine gewisse biologische Beziehung zwischen Hypophysis und Schilddrüse wollten mit ihren Untersuchungen Schnizler und Ewald (Wiener klin. Woch. 1896) beweisen, die in der Hypophysis Thyreoiodin fanden und bemerkten, daß es so wie gewisse Produkte der Schilddrüse wirkte.

2) Vassale, Rivista sperimentale di Freniatria, Vol. 27, 1901.

3) Tizzoni \& Centanni, Archivio per le Scienze Medíche, Vol. 14.

4) Leonhardt, Dieses Arehiv Bd. 149, H. II. 
Gewicht der Schilddrüse [siehe Tabelle ${ }^{1}$ )], ohne daß die Hypophysis von ihrem mittleren Gewicht abwich.

Gegen das angenommene Verhältnis von Gegenseitigkeit der beiden Organe möchte ich den Befund von Bonardi vom Jahre 1893 (a. a. 0.) und jenen kürzlich veröffentlichten von Ponfick ${ }^{2}$ ) über zwei Kranke anführen, von denen der eine an Akromegalie, der andere an Myxödem litt, welche zwei Krankheiten nahe miteinander verwandt sind. Sowohl in dem einen als in dem andern Fall bestand sklerotische Atrophie der Hypophysis and der Schilddrüse. Im Falle von Bonardi erschien allerdings die Hypophysis eher groß $(2,975 \mathrm{~g})$, aber die Zunahme kam ganz auf Rechnung des Bindegewebes und der Blutgefäße, während die epithelialen Stränge des Vorderlappens ausgesprochen atrophisch waren. Auch die grundlegenden Untersuchungen ron Rogowitsch, welche den Anstoß zur Hypothese der kompensierenden Funktion zwisehen Hypophysis und Schilddrüse gegeben haben, scheinen mir diese Ansicht nicht $\mathrm{zu}$ bestätigen; denn auch seine Tierexperimente geben mir Anlaß, diese angenommene gegenseitige Funktion der zwei Organe für sehr problematisch zu halten. Zwar ist es richtig, daß bei den Tieren mit von Rogowitsch exstirpierter. Schilddrüse die Hypophysis an Volumen zunimmt, aber die histologische Untersuchung zeigt, dab im Vorderlappen dies durchaus das Werk der Hauptzellen ist, denen die modernen Ansichten mit Recht die Bedeutung von Elementen im Ruhezustand zuschreiben. Wenn wir den Arbeiten von Tizzoni und Centanni (a. a. 0.) and Stieda ${ }^{3}$ ) folgen, so finden wir überall den gleichen Befund, daß nämlich in der Hypophysis ihrer Tiere mit exstirpierter Schilddrüse die Hauptzellen zugenommen und die Chromophilzellen abgenommen haben, außerdem zeigt sich eine reichliche Vakuolenbildung in den Zellen, welche

1) Tabelle.

\begin{tabular}{cc|c|cc} 
& Fall & \multicolumn{2}{|c|}{ Alter } & Gew. d. Schild. \\
\hline I & 55 & $7 \frac{7}{2}$ & 2,3 & $\mathrm{~g}$ \\
II & 11 & $7 \frac{1}{2}$ & 10,9 & \\
III & 28 & 8 & 4,3 & $"$ \\
IV & 26 & 11 & 12,0 & $"$ \\
V & 109 & 11 & 20,0 &
\end{tabular}

2) Ponfick, Zeitschrift für klin. Med., Bd. 38. 1899, S. 1.

3) Stieda, Zieglers Beiträge, Bd. V. 1890. 
schon von Rogowitsch erwähnt wurde und die man gewib nicht für den Ausdruck einer Funktionszunahme halten darf.

Die modernen Ideen über die Bedeutung der Chromophilzellen entziehen also dem hypothetischen Parallelismus in der Funktion der Hypophysis and jener der Schilddrüse den Boden, und lassen den Zweifel entstehen, ob nicht zufällig bei der experimentellen strumipriven Kachexie und beim spontanen Myxödem die Vergrößerung der Hypophysis in dem ganzen Krankheitsbild als an und für sich bestehendes Symptom anzusehen ist (Vassale), welches im Gegensatz zum angenommenen Gegenseitigkeitsverhältnis ganz und gar nicht von der Exstirpation oder von der spontanen Atrophie der Schilddrüse abhängt.

Die Ansicht, daß eine gegenseitige Kompensation zwischen beiden Organen nicht besteht, wird auch durch meinen Fall bestärkt, da trotz der schweren Hypophysisatrophie und des absoluten Fehlens von Chromophilzellen, bei der histologischen Untersuchung der Schilddrüse Zeichen einer funktionellen Hyperplasie nicht zutage traten.

\section{Fall II.}

Hypophysis-Tumor mit Akromegalie.

Die interessanten Angaben aus der Anamnese, objektiven Untersuchung and aus dem Sektionsbefund verdanke ich Herrn Dr. Baggio, der mir in liebenswürdigster Weise den in einem wenig verbreiteten Blatt publizierten Fall zur weiteren Bearbeitung überlassen hat, dem Sektionsbefund konnte ich eigene Beobachtungen hinzufügen.

Viktor Piziol, 35 Jahre alt, in Venedig von gesunden Eltern geboren. Weder direkt noch in der Seitenlinie erblich belastet. Ungewöhnlich kräftig, hatte er seit seiner Jugend schwer gearbeitet und war dabei der feuchten Kälte ausgesetzt gewesen. Er verheiratete sich mit 20 Jahren und hatte 8 Söhne, von denen 3 in der Kindheit starben, während 5 sich in voller Gesundheit des Lebens erfreuen. Bis zum 24. Lebensjahre bot seine Anamnese in pathologischer Beziehung nichts Interessantes dar. In dieser Zeit litt er an Scharlach, und gleich darauf begann er mit unbestimmten Symptomen zu kränkeln, mit Nachtschweißen, heftigen Muskel-, Gelenkund Kopfschmerzen. Dadurch verminderte sich die Arbeitslust and Arbeitsfähigkeit. Der hauptsächlich auf der linken Seite bestehende Kopfschmerz verstärkte sich langsam, verbunden mit zunehmender Schwäche der Sehkraft auf der korrespondierenden Seite und mit allmählicher Vergrößerung des Kopfes, der Hände und Fübe. Die von Beginn der Krankheit an angewendete Behandlung konnte den progressiven Verlauf derselben nicht 
aufhalten. Der Patient, der zuletzt noch an Nierenentzündung litt, begab sich in das Bürgerspital von Venedig, wo er bis zu seinem Tode verblieb.

Die objektive Untersuchung ergab: Mann unter mittelgroß $(1 \mathrm{~m} 61 \mathrm{~cm})$, in gatem Ernährungszustande, mit ziemlich blasser Hant und anämischen Schleimhäuten. Das linke Auge steht heraus, sieht nach außen und etwas nach oben. Kopfumfang groß, mißt $61 \mathrm{~cm}$, der Längsdurchmesser 18,7, der quere $16 \mathrm{~cm}$. Lippen fencht, besonders die Untexlippe, walstig, negerartig hervortretend, Prognatismus, Jochbeine und Augenhöhlenränder stark ausgebildet, Nase und Ohrläppehen dick und fleischig. Zunge dick, Kyphose an der Hals-Brustwirbelsänle, Atrophie der Hoden; Zengungsfähigkeit seit 2 Jahren erloschen. Perkussion und Auskultation ergaben am Thorax und Abdomen nichts Besonderes. Hand- und Fußmaße sind folgende: Umfang der Faust 31, des Daumens 10, des Zeigefingers 8,3, Fußumfang in der Höhe der Metatarsi 28,5, der großen Zehe am Nagelglied $11,8 \mathrm{~cm}$. Füße und Hände sind derartig dick und groß, daß man sie für einem Riesen gehörig halten konnte. Die Finger erscheinen wurstförmig geschwollen. Keine Störung der Sensibilität und Reflexerregbarkeit. Außer den schon erwähnten Augenstörungen ist eine Abschwächnng des Geruchund Gehörsinns zu bemerken. Urin ohne besonderen Befund.

Patient starb am 18. März 1902, das Sektionsprotokoll ist unglücklicherweise unvollständig, nur die Untersuchung der Schädel- und Rückenmarkshöhle und des cervicalen Sympathicus ist geschildert. Der äußeren Körperformation entsprechend sind die Skelettveränderungen der Glieder und des Kopfes, die schon in der Krankengeschichte erwähnt sind, besonders hervorgehoben. Was die Brust- und Bauchorgane anbetrifft, so konnte ich in Erfahrung bringen, daß das Herz enorm vergrößert war, ein wahres Cor bovinum, ohre daß Klappenfehler existierten; und daß die Leber ganz ungewöhnlich grob war, obwohl ihre Struktur intakt erschien. An den Nieren fand sich eine chronische, parenchymatöse Entzündung. Die Lücken des Sektionsbefandes lassen leider eine der sehweren Anomalie des Zentralnervensystems entsprechende genane Feststellung körperlicher Störungen nicht zu; die cerebrospinalen Veränderungen waren in der Tat ungewöhnlicher Art, wie aus dem folgenden hervorgeht.

Schon die Bildung und Symmetrie der Schädelknochen bot nach Entfernung des Schädeldachs auffällige Befunde dar. Die linke vordere Schädelgrube war tiefer als die rechte und ebensoviel tiefer als die mittlere derselben Seite: das linke Felsenbein sprang infolgedessen mehr nach oben vor, als das rechte. Die Cellnlae mastoideae rechts waren sehr viel weiter als normal. Der interessanteste Befund war jedoch das Vorhandensein eines Tumors, der aus der Gegend der Hypophysis gegen die Gehimbasis sich erstreckte, mit welcher er durch leichte Adhäsionen zusammenhing. An der Konvexität der Großhirnhemisphären fand sich nichts Bemerkenswertes; nur die weichen Hirnhäute waren etwas opak, ließen sich jedoch überall leicht abziehen, mit Ausnahme des Trigonum olfactorium, wo nach innen von den Nervi olfactorii und optici eine kleine 
fibröse Adhäsion vorhanden war. Der erwähnte Tumor der Hypophysengegend nahm die ganze Sella turcica ein und reichte einen Danmen breit nach oben über den Processus clinoid. anterior hinaus, er bildete eine grau rosafarbene höckerige Masse, die auf der Oberfäche von einer dümnen, transparenten Membran wohl begrenzt war, die sie von der Gehirnbasis trennte. Ein kleiner, kenlenfömiger Anhang ging von der linken Tumor-

\section{Hypophysistumor mit Akromegalie (Fall Piziol).}

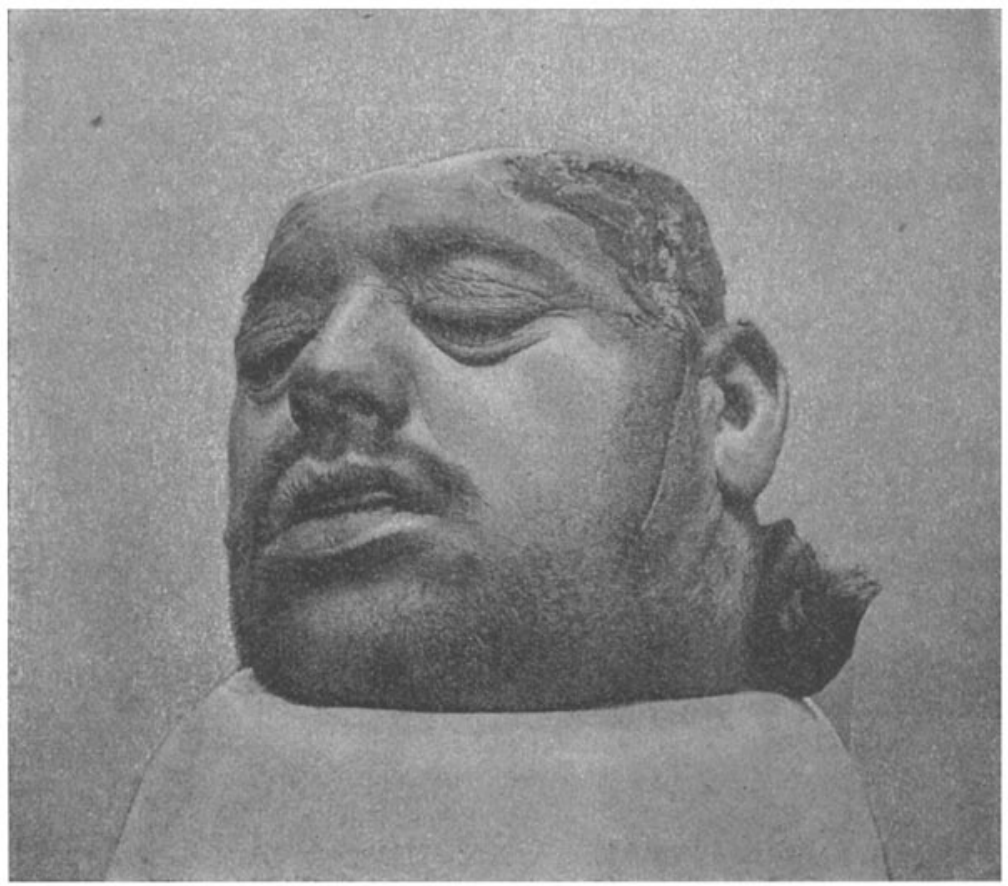

Fig. 3.

Akromegalische Gesichtsdeformität.

halfte aus und setzte sich unter der Dura mater über dem linken Nervus opticus am Foramen opticum an, ohne jedoch darüber hinauszugehen. Der Tumor, der in ganzen die Größe eines kleinen Hühnereies hatte, war ziemlich derb, an der Peripherie und im oberen Abschnitt von einer hirnähnlichen Konsistenz, in Zentrum und an dem in der Sella turcica gelegenen Teile indessen weich, schwammig und fast breiig. An seiner Oberfäche fanden sich keine Spuren vom Peduneulus pituitarius. Von den beiden inneren Carotiden ging die rechte einfach an dem Tumor dicht vorbei; die linke dagegen war überall von Tumor ungeben komprimiert. 
Das Dach der Sella turcica war zerstört, die Lamina quadrilatera des Keilbeins in ihrer oberen Hälite asuriert, derart, daß die proc. clinoid. poster. fehlten. Auch der Knochen auf dem Boden der Sella turcica war auf der linken Seite usuriert; jedoch ging der Tumor nach unten nicht weiter, die Keilbeinhöhlen waren vollständig frei. Der Tumor erreichte nicht die mittlere und die seitlichen Hirnhöhlen, das Kleinhirn war intakt.

Hypophysistumor mit Akromegalie (Fall Piziol).

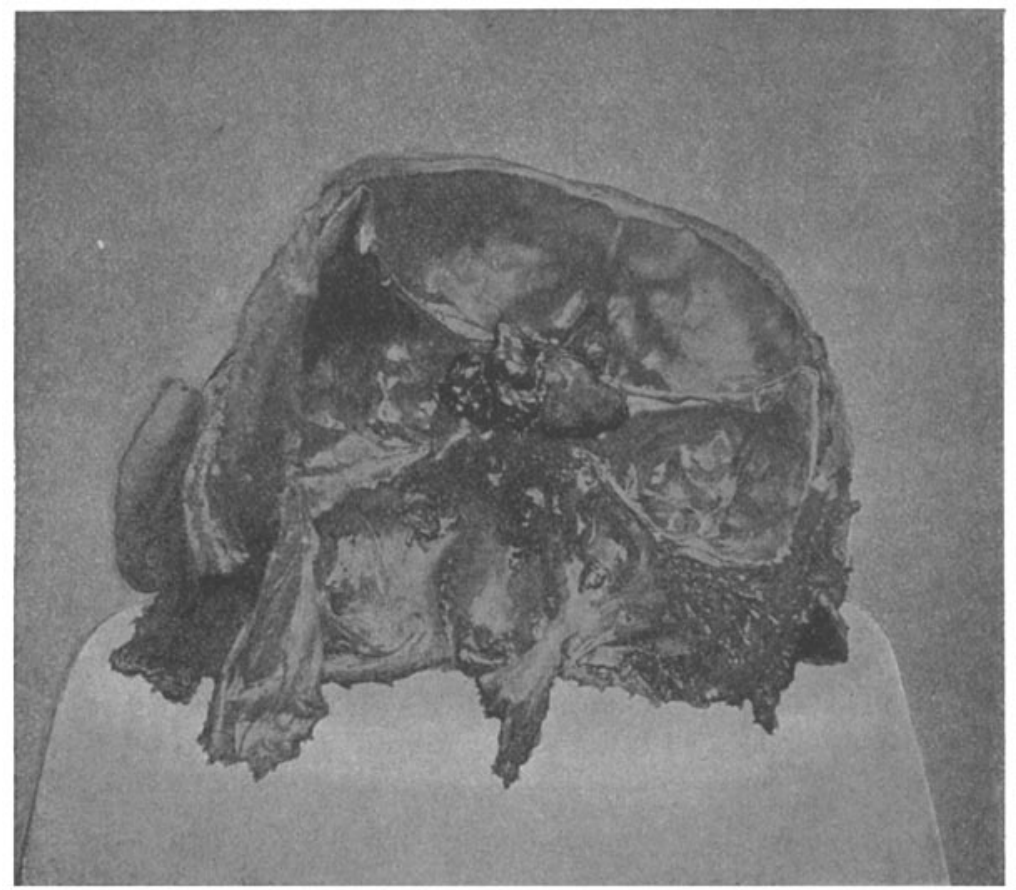

Fig. 4.

Ansicht des Tumors nach der Trennang vom Gehirn.

Die mikroskopische Untersuchung der Halsganglien des Sympathicus hatte kein besonderes Resultat. Das von der Dura mater befreite Rückenmark zeigte sich jedoch im ganzen verdickt, jeder einzelne Teil hatte eine ungewöhnliche Größe; die Lendenanschwellnng war fast ebenso gro B, als bei einem mittelgroßen, gut entwickelten Manne die Halsanschwellung zu sein pflegt.

Die Maße, die mir in liebenswürdiger Weise vom Prosektor zur Verfügung gestellt wurden, ergaben folgende Zablen:

Halsanschwellung: sagittal $11 \mathrm{~mm}$, frontal $18 \mathrm{~mm}$, Umfang $46 \mathrm{~mm}$; mittlerer Brustteil: Lendenanschwellung:

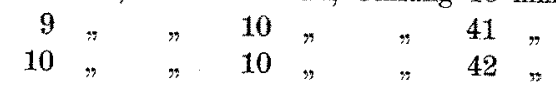


Ich kontrollierte die Maße an den Querschnitten durch das ganze Mark, die Dicke der weichen Haut und der unter der Pia gelegenen Tumormasse wurde dabei nicht berïcksichtigt, davon werde ich nachher sprechen, lier gebe ich die absoluten Zahlen für die Rückenmarksdicke. Die relativen Zahlen umfassen (auBer bei der Halsanschwellung, die fast frei von neoplastischer Infiltration war) neben der absoluten Dicke des Markes anch noch die Dicke der zarten, neoplastischen Umbüllung, sie sind daher mit einer gewissen Freiheit zu geben.

Wenn man die Zahlen dieses Falles mit den normalen nach Le Tes tu t ${ }^{1}$ ) und Sterzi ${ }^{2}$ ) vergleicht, so erkennt man sofort, daß es sich hier um eine allgemeine Vergrößerung des gesamtes Markes handelt, an der besonders die obere Partie, der Halsteil, beteiligt ist, daselbst liegt das Maximum der Differenz (18 gegen $13 \mathrm{~cm}$ normal auf dem Frontaldurchmesser).

Weitere interessante Daten gaben die Größenverhältnisse der granen und weißen Substanz des Rückenmarks in verschiedenen Höhen. Genaue Zahlen kann ich jedoch nicht geben, weil dazu eine besondere Übnng in dieser Art der Untersuchning gehört, die ich nicht besitze. Ich beschränke mich daher auf die Angabe, daß beim normalen Rückenmark ebenso wie bei dem in Frage stehenden das Verhältnis zwischen weifer und graner Substanz in der Cervical- und Lumbalanschwellung derart ist, daß die graue Substanz in der Lendenansehwellung eimen relativ größeren Raum einnimmt, als in der Halsanschwellung, daher waren im Halsteil im Vergleich zum normalen Befunde dünne, atrophische Vorderhömer neben dicken, weißen Strängen zu finden. Die ganze graue Figur war verkleinert, dagegen erschienen die Hintex-, besonders die Seitenstränge ungemein verdickt. Die Masse der weißen Substanz überwog daher in großer Ausdehnung die der grauen, und zwar war die Differenz viel größer, als in normalen Fällen. In seiner Gesamtheit zeigte ein Transversalschnitt durch die Halsanschwelling ein Bild, in Bezug auf Dicke und Verteilung beider Substanzen, wie man es normalerweise aus dem mittleren Brustmark eines Pferdes erhält.

Uber die Gesamtlänge des Rückenmarkes kann ich nichts Bestimmtes sagen, weil die unvollständigen Sektionsangaben nichts darüber aussagten; nach den mir verbliebenen Stücken schien es sich nicht sehr von einem normalen zu unterscheiden. Ferner war bemerkenswert, daf längs des ganzen Marks kleine Excrescenzen bestanden, sie lagen unter der Pia, waren rundlich, gran, ganz klein am oberen, etwas größer am Lendenteil und Conus terminalis, wo sie die Größe eines Hirsekorns erreichten; sie waren regellos verteilt, am unteren Abschnitt am zahlreichsten, zwischen den Nervenstämmen der Canda equina fanden sie sich in geringer Zahl unter dem Perineurium, immer von graner Farbe und rund. An einigen

1) Le Testut: Traité d'anatomie.

2) Sterzi: Untersuchungen, betreffend die vergleichende Anatomie und Entwicklung der Meningen. Atti del R. Istit. Veneto di Scienze, Lettere ed Arti, Tom. LX, 1901. 
Stellen bildeten mehrere nebeneinander liegende Excrescenzen kleine, maulbeerförmige Knoten. Auf dem Durehschnitt erschienen sie bei 8- bis 10 facher Vergrößerung scharf begrenzt, mit blobem Auge sah man nur, dab sie mit dem Nervenast oder dem Rückenmarksstrang, an dem sie saben, verschmolzen waren; in ihrer Konsistenz stimmten sie mit der des Rückenmarks überein. Es handelte sich offenbar um feinere Metastasen des Hypophysentumors am Rückenmark.

Die makroskopische Untersuchung dieses Akromegaliker - Markes ergab also:

1. Vergrößerung des ganzen Rückenmarkes, speziell des Cervicalteils.

2. Veränderung im Verhältnis der weißen zur graxen Substanz.

3. Dissemnierte Geschwulstbildungen unter der Pia: Metastasen des intracraniellen Trumors.

Zur mikroskopischen Untersuchung standen mir Stücke aus dem Cervical-, Dorsal- und Lumbalteil zur Verfügung, sowie einige Canda equinaÄste mit den anliegenden metastatischen Knoten. Außerdem erhielt ich durch die Güte des Herrn Cavagnis fast den ganzen Tumor der Glandnla pituitaria, zum Teil in Paraffin eingebettet, zum Teil in Müllerscher Flüssigkeit, schließlich hatte ich selbst noch einige Wochen nach der Sektion Gelegenheit, mir aus der Sella tureica Tumorstüekchen, die an der Knochenwand hängen geblieben waren, herauszuschneiden. Zu dieser Zeit hatte der Trmor natïrlich seine Farbe verloren und von der Fixationsflüssigkeit eine gelb-grünliche Färbung angenommen.

Soviel Stücke des Tumors ich auch nachher untersuchte, und zwar richtete ich meine besondere Aufmerksamkeit auf die aus der Sella turcica stammenden Teile, nirgends konnte ich eine Spur von hypophysisähnlichem Gewebe entdecken. Es fehlten also besondere Anhaltspunkte, besonders auch ein Stiel, wie er der Hypophysis eigen ist, dadurch hatte die Untersuchung ein sehr beschränktes Interesse. Rü̈ckenmarksstücke aus verschiedenen Höhen, in Müllerscher Flüssigkeit konserviert, behandelte ich nach Marchi, und andere mit gutem Erfolge mit Alizarinblau nach Benda. Ich hatte dabei bessere Resultate, feinere Details, distinktere Färbungen, als wenn ich die Vorschrift Bendas befolgte (Fixation in 10 p.c. Formol, härten in Chromsäure von steigender Konzentration bis 0,5 p. c.). Stücke vom Hypophysistumor und den Metastasen in der Cauda equina erhielt ich nach derselben Behandlung nicht weniger ausgezeichnet, wahrscheinlich ist die langsame Imprägnation mit dem in der Müllerschen Flüssigkeit enthaltenen Chromsalz und die folgende Beizung mit Eisen-Alaun Schuld an der zarten Färbung der Schnitte.

Die Untersuchung der Geschwulst auf Hypophysisreste und auf eventuelle Beziehungen dieser Reste zur Geschwulstbildung war mit bloßem Auge erfolglos, sie mußte durch mikroskopische Kontrolle gesichert werden, dabei glückte es, ebenso wie in Fall $I$, auch hier bei Anwendung von Serienschnitten, in dem intrasellaren Teil des Tumors Stellen zu finden, die unzweifelhaft dem Hypophysisgewebe anzugehören schienen: kleine 
Bänder eines tubulösen Gewebes mit Colloidmassen in ihrem Innern. Auch Ubergänge zwischen diesen Resten und der Neubildung zu finden, gelang mir mit unzweideutiger Klarheit, ungeachtet der großen Brüchigkeit, die der Tumor durch das lange Liegen in Müllerscher Flüssigkeit angenommen hatte. An den Stellen, die ich für Reste des drüsigen Hypophysisteiles halte, sieht man Bildungen von schlauchförmigem Charakter, rund oder elliptisch, die einen dicht neben den andern in der Weise liegend, $\mathrm{da} B$ das zarte Septum, das den einen Herd begrenzt, gleichzeitig auch dem daneben liegenden als Septum dient. Zwischen den Schläuchen liegen auch feinwandige, stark gefüllte Blutgefäße. Auf einer Basalmembran lag ein ziemlich niedriges, knbisches Epithel in einfacher Lage, eine mit Toluidinblau tiefblau gefärbte Colloidmasse umschließend oder mit einem feinkörnigen Detritus im Innern, der wahrscheinlich aus Zerfall epithelialer Elemente entstanden war. Epitheliale Elemente fanden sich in den Hohlräumen sehr selten; wo sie vorhanden waren, waren sie rundlich, unscharf begrenzt, fast stets ohne Kern und kleiner als die der Basalmembran aufsitzenden. Letztere hatten dagegen immer einen kleinen, runden, intensiv gefärbten Kern, der dicht an der Basis der betreffenden Zelle saß. Diese Zellen waren bald deutlich voneinander getrennt, bald bildeten sie, miteinander verschmolzen, vielkernige Protoplasmasäume. Erwähnenswert ist das homogene Aussehen, das alle diese Zellen darboten, sie färbten sich blaBrosa nach der Bendaschen Methode sowohl, wie mit Eosin, ohme auch nur die geringste Granulation erkennen zu lassen. Nach allem muß man diese Elemente für chromophob halten, sie gehören wohl zu der Peremesko schen Marksubstanz.

Von diesen Stellen mit schlauchförmiger Anordnung fanden wir allmähliche Obergänge zu mäBig weiten alveolären Räumen. Hier war nur spärliches Bindegewebe dazwischen vorhanden, in ihm lagen Blutkapillaren von weiterem Kaliber, als die zwischen den obenerwähnten schlauchförmigen Bildungen. Die in den Alveolen enthaltenen Zellen waren gemä̈B ihrer Weite zahlreicher, als in den Zellschläuchen, waren aber nicht so regelmäßig wie dort angeordnet, bildeten also keine einfache, auf der Alveolarwand sitzende Zelllage, sondern waren regellos im Lumen verteilt, ăhnlich wie im vorderen und mittleren Abschnitt des glandulären Teiles einer normalen Hypophysis.

Das größte Interesse verdient das Verhältnis zwischen der Forn der in diesen Alveolen enthaltenen Zellen und ihrer Reaktion auf die verschiedenen Färbungen. Die Zellen waren von ungefähr gleicher Größe wie die Epithelien im glandulären Hypophysisabschnitt and ebenso wie diese an Größe und Form wechselnd. Einige von ihnen waren rundlich, andere polygonal mit abgestumpften Ecken, noch andere dreieckig oder birnförmig, und ihr größter Durchmesser betrug einerseits 8-10, andererseits $16 \mu$, die runde Form herrschte indessen bei weitem vor. Der Kern war einfach oder doppelt, rund und oft undentlich infolge der starken Färbung, welche das Protoplasma annahm; letzteres war hier so reich an 
Granulationen, daß der ganze Zellleib wie ein dichter Körnchenhanfen aussah. In anderen Zellen dagegen waren die Granula nicht so reichlich, sie lagen dann entweder am Rande des Protoplasmas oder waren auf eine Stelle zusammengehäuft. Immer waren die Granula jedoch scharf voneinander getrennt und nicht wie bei den Zellen der erst besehrieben Art, miteinander zu Klumpen verschmolzen. In anderen Zellen endlich, und zwar in einer verhältnismäBig Kleinen Zahl, nahm das Protoplasma nach der Bendaschen Methode eine tiefrote Farbe an, ohne dab man das kleinste Granulum entdecken konnte, gewöhnlich waren diese Zellen kleiner als die anderen, hatten unscharfe Ränder und unregelmäßige Form. Man würde sie besser "Zellreste" als Zellen nennen, auch schon deswegen, weil der Kern nur in einigen wenigen noch erkennbar war. Auch in den drüsenähnlichen großen Räumen fanden wir an der Wand oder im Lumen kleine, vereinzelte, rundliche, homogene Klumpen, die sich mit SchwefelAlizarin tiefrosa färbten und scharf konturiert waren: an der kolloiden Natur dieser Substanz konnten keine Zweifel bestehen, da sie dieselben Farbenreaktionen gab und ebenso aussah, wie die oben beschriebene, in den Zellschläuchen liegende. Von diesen an den glandulären Hypophysisabschnitt erinnernden Bildern ausgehend kommt man stufenweise auf gewisse Stellen, an denen nur noch eine adenomatöse Anordnung zu sehen war, große, zellreiche Alveolen, aber ohne die charakteristischen Zellgranula, so daß hier die sog. Chromophoben vorherrschten. Einer solchen inneren Veränderung der Zellen entsprach auch die Art, sich aneinander zu legen, and die Größe, es bestanden hier richtige kompakte Zellstränge, die auf feinen, blutgefäßarmen Bindegewebssepten saßen, und zwischen den Zellhaufen konnte man Elemente erkennen, die viel umfangreicher waren, als die in der vorigen Zone beschriebenen, von polygonaler Form oder rund, mit drei bis vier Kernen. Manche von diesen großen Zellen enthieiten auch spärliche Granula in ihrem Protoplasma. Colloidklumpen zwischen diesen Zellen fehlten vollkommen. Gleichzeitig sieht man, wie die Septen des Stromas feiner werden, sogar verschwinden und so die Alveolen zu weiteren Hohlräumen zusammenfließen: innerhalb spärlicher und mehr feiner Bindegewebstrabekel liegen hier Haufen von Zellen, von denen nur sehr wenige noch durch ihre Form und Protoplasmakörnung an die chromophilen Zellen der Hypophysis erinnern. Blutgefäße waren im Zentrum des Tumors spärlich vorhanden.

Interessante Resultate brachten die Disseminationen der Neubildung auf der Rückenmarksoberfläche und den Cauda equina-Strängen: alle zeigten Ubereinstimmung in ihrem Bau. Entsprechend der Verteilung besagter Knoten, wie man sie mit schwacher Vergrößerung auf Rückenmarksquerschnitten verschiedener Höhen sieht, bemerkt man, daß, je weiter man vom Halsteil zur Lendenanschwellnng hinabkommt, desto ausgedehnter die Geschwulstinfiltration wurde. In den oberen Abschnitten beschränkte sie sich auf einen kurzen Teil der Peripherie und trat unter der Form wenig hervortretender halbkngeliger oder maulbeerförmiger Excrescenzen 
auf. die bei schwacher Vergrößerung kaum erkembar waren, nach außen von einer zarten, fibrillären Membran begrenzt. Nach unten hin wurden die Knoten dagegen immer zahlreicher, größer, ihre Ursprünge verschmolzen miteinander zu einer Art perimedullärer, discontinuierlicher Umhïllung mit ausgebuchtetem Rande, auch dem bloßen Auge wohl erkennbar. Die Grenze zwischen Mark und Tumor war anf all den zahlreichen Schnitten, die ich untersuchte, immer scharf, und miemals schienen mir Neubildungen von der Peripherie aus zwischen die Faserstränge einzudringen und sie zu zerstören. Nur an den groben Sulci mediani ant, und post. drangen sie durch den Rand ins Innere, ohne jedoch in der Tiefe dieser Sulci weiter um sich zu greifen. Zerstörungen nervöser Fasern auf Kosten dieser Neubildungen fand ich jedoch an der Cauda equina. Hier hatten sich die Tumorzellen nach Zerstörumg des Perineuriums bis ins Zentrum des Nerven freie Bahn gemacht, indem sie eine Faser nach der andern durchsetzten. Infolgedessen waren hier einige Nervenäste zerstört, viele ihrer Fasern waren verändert und von Tumorzellen zusammengedrückt, noch andere auf einfache Achsencylinder reduziert, indem sie ihre Mark- und Schwannsche Scheide verloren hatten. In solchen Nervenästen war ein guter Teil vollständig von Geschwulstzellen eingenommen, zwischen denen man Fragmente von Achsencylindern und Myelintröpfehen bemerkte. Betreffs der Anordnang, Form und Natur der metastatischen Tumorzellen ist $z \mathfrak{u}$ bemerken, daß drüsenähnliche Bildungen, wie sie im intracraniellen Tumor vorkamen, hier vollständig fehlten. Das Bindegewebsgerüst andererseits war spärlich, nur an einzelnen Stellen lagen feine Bündel oder einzelne Fasern, miteinander weite Räume umschließend, in denen dichtgedrängt die Tumorzellen lagen. Diese zeigten die verschiedensten Formen: rundlich, oval oder unregelmäBig polygonal. In einzelnen war der Kern einfach, relativ grob, rund, und nahm fast den ganzen Zellleib ein, in anderen dagegen überwog das Protoplasma an Ausdehnung den Kern und bildete einen breiten Hof um denselben: diese zweite Art von Zellen war anch gröBer. Daneben bestanden auch noch Riesenzellen mit 3, 4 Kernen, ähnlich den im Primärtumor gefundenen. Das Protoplasma aller dieser differenten Zellen war ziemlich blaß und nahm nach der Bendaschen Methode eine mehr oder weniger tiefrosa Farbe an, der Kern dagegen war äuBerst reich an Granula und Chromatinfäden, die sich besonders im Zentrum in einer gewissen regelmäBigen Lage vorfanden. Im Gegensatz zu diesen Zellen fanden sich vereinzelt auch solche, die ein stark lichtbrechendes, granuliertes Protoplasma hatten, mit Toluidinblan färbte es sich dunkelblau, so daß der Kern wie ein helles Körperchen von dem dunklen Grunde sich abhob.

Die Blutgefäße waren anch in den Metastasen ziemlich zahlreich, viele derselben gehörten zweifellos dem Gefäßnetz der Pia mater zu, vermittelst dessen der Transport der Geschwulstzellen zustande gelkommen war. Im Lumen solcher, der Länge nach getroffener Kapillaren konnte jch zwischen den roten Blutkörperchen Elemente nachweisen, welche nach Form, Größe, Färbbarkeit den Gesehwulstzellen ähnlich waren: Meta- 
stasis auf dem Blutgefäb̂wege. Keine Beziehung hatten diese Zellen zum GefäBendothel, das man vielleicht für ihre Entstehung hätte heranziehen können, schon im Aussehen unterschieden sie sich von den Endothelien. Die wenigen Zellen, die ich sehen komte, waren groß, etwa dreimal so groB als ein rotes Blutkörperchen, hatten ein ziemlich reichliches Protoplasma und wurden mit Toluidinblau intensiv dunkelblau gefärbt; ihr Kern, rund und in der Einzahl, hob sich als glänzender Körper vom Protoplasma ab.

Weder im Primärtumor, noch in den Metastasen bestanden Degenerationsprodukte oder Vakuolen, man sah jedoch, wie schon erwähnt wurde, kleine Zellen ohne Kern und Zelltrümmer, ohne Fett, d. h. es bestand unter den Zellen der Neubildung das Bestreben, nekrobiotisch zu werden, oder sie waren schon abgestorben. Colloidklumpen sah ich in den Metastasen nicht, trotz langer daraufhin gerichteter Untersuchungen. Es fehlten auch sowohl im Primärtumor als in den Metastasen Kernteilungsfiguren, ich glaube dies, zum Teil wenigstens, auf die' für die Untersuchung wenig geeignete Fixationsmethode in Müllerscher Flüssigkeit zurückführen zu dürfen.

\section{Rückenmark.}

Bei der Untersuchang von Querschnitten, nach den verschiedenen bekannten Methoden gefärbt, fand man besonders an den höheren Segmenten die Zahl der die Stränge zusammensetzenden Fasern vermehrt, sie lagen dichter als normal und zeigten die mannigfachsten Größenverhältnisse. Einige hatten höchstens $2-3 \mu$ Durehmesser, daneben befanden sich solche, deren Dicke schon ohne weiteres in die Augen sprang, die bis zu 36 und $37 \mu$ maßen. Nach der von Flechsig eingefürten Klassifikation in dicke, mittlere und dünne Fasern muB man ohne weitere Untersuchung annehmen, daB hier die Fasern der ersten Kategorie reichlicher vorhanden sind, als im Rückenmark eines gleichalterigen normalen Individnums. Anch in den tiefen Abschnitten des Seitenstranges, wo normalerweise die feinen Fasern sehr zahlreich und die dicken spärlich sind, waren die letzteren, besonders auf der rechten Seite, reichlich vorhanden. Dieselbe Erscheinung zeigte sich in dem Teil des Gollschen Stranges, der dem Sulcus posterior anliegt; hier gab es neben den dicken Fasern auch zahlreiche Corpora amylacea.

Instruktiver gestaltete sich die Untersuchung an Schnitten, die der Längsachse parallel geführt wurden, man erkannte da auf jedem Schnitt neben den Fasern, die wie die normalen von einer einfach welligen Markscheide umgeben waren, solche, die eine von rundlichen und spindelförmigen, verschieden großen Anschwellungen besetzte Scheide in ihrem Verlaufe aufwiesen. Nach der Marchischen Methode zeigten sich die einzelnen Varicositäten leer, so daß nur ihr Kontur schwarz gefärbt war. Diese Art und Weise im Verhalten der Markscheiden erklärte es, wieso trotz der schweren Modifikationen dieser Scheiden die Myelinmassen und -tröpfehen spärlich waren. Es zeigte sich so auch, wie die Fasern mit 
großen Durchmesser, die so zahlreich in den Quersehnitten gefunden wurden, wenn nicht alle, so doch die meisten den optischen Durchschnitten der obengenannten Markansehwellungen entsprachen. Mit derselben Marchischen Methode konnte man sehen, wie das Lipochrom in einigen Ganglienzellen, die in der grauen Substanz verstreut lagen, leicht vermehrt war, es nahm dann in Form grobkörniger Massen eimen großen Teil des Zellleibes ein.

Das Stïtzgewebe zeigte eine gewisse Hyperplasie der Neuroglia, in der Peripherie jedoch nur an den Stellen, an welchen unter der Pia die Metastasen saßen. Die Blutgefäße waren überall stark gefüllt, in ihrer Nachbarschaft fanden sich keine Spuren von zelliger Infiltration oder von Blutungen.

Ein besonderes Interesse bot auch das Verhalten des Zentralkanals dar. Er war in seinem ganzen Verlauf vollständig mit Zellen ansgefüllt, die im Bau den normalen Ependymzellen ähnlich waren, von cylindrischkonischer Form oder unregelmäßig gestaltet infolge des gegenseitigen Druckes und wegen des dichten Aneinanderliegens im Lumen des Kanals. Nach der Bendaschen Methode wurde das Protoplasma gleiehmäßig blan gefärbt, der Kern war rund, arm an Chromatin und fast immer excentrisch. Zwisehen den Zellen lagen Gliafasern, entweder in ihrer Längsachse getroffen oder im Querschnitt als rote Pünktchen erscheinend. Einige dieser Zellen, welche ich für nervöse Elemente halte und für Abkömmlinge vom Epithel des Kanals, durchdrangen in geringer Anzahl die sog. Substantia gelatinosa centralis am Rande des Kanals und die graue Commissur.

Mit Bezug auf den histologischen Befund des Rückenmarks könnte wohl ein Zweifel entstehen, ob nicht vielleicht einige der beschriebenen Veränderungen der Nervenfasern nur die Folge der am Kadaver erfolgten, oder durch die Behandlungsweise hervorgerufenen Umgestaltungen seien. Der Vergleich zwischen den Präparaten dieses Markes eines Akromegalischen und anderen von gleichaltrigen, nicht neuropathischen Individuen, deren Rückenmark ich in gleicher Weise, wie das des Alrromegalischen behandelte, die also dem Leichnam im Frühling ungefähr 40 Stunden nach dem Tode entnommen, mehrere Monate in Müllerscher Flüssigkeit gehalten und dann nach Bendas Methode gefärbt wurden (SulphoalizarinsäurenatronToluidinblan) bringt mich dahin, anzunehmen, daß es sich in diesem Falle um wirkliche pathologische Veränderungen handelt. Diese Überzeugung bestärkt sich in mir noch durch andere Erwägungen.

Im Rückenmark des Akromegalischen fand sich eine so 
bedeutende makroskopische Anomalie (Makromyelie), daß sie gewiß nicht für postmortal gehalten werden darf; außerdem fehlte eine Cbereinstimmung zwisehen den, anch in den zentralsten Teilen der Stränge vorhandenen Läsionen der Nervenfasern und denjenigen der Nervenzellen, welche gewöhnlich bei am Kadaver erfolgten oder durch die technische Behandlumg hervorgerufenen Umgestaltungen nicht mangelt (Schult ${ }^{1}$ ) Sfameni ${ }^{2}$ ).

Dazu muß noch bemerkt werden, daß das Rückenmark des Akromegalischen ungefähr 40 Stunden post mortem dem Kadaver entnommen wurde und zu einer Jahreszeit (März), wo wegen der niederen Temperatur die Verwesungssymptome nur spät zum Vorschein kommen und langsam verlaufen.

Das anatomische Studium dieses zweiten Falles ist also von hoher Wichtigkeit nicht nur wegen den vorerwähnten Veränderungen des Rückenmarks, sondern auch wegen des besonderen histologisehen Befundes des Hypophysistumors und wegen des Interesses, den dieser Befund, in bezug auf die Pathogenese der Akromegalie beanspruchen darf. An der Genaxigkeit der klinischen Diagnose auf Akromegalie konnte kein Zweifel entstehen. Das Erscheinen von Knochenveränderungen im Alter von ungefähr 26 Jahren und ihr langsames und symmetrisches Zunehmen, die Kyphose des oberen Brustwirbels, der vorspringende Unterkiefer, die Vergrößerung und Verdickung der Lippen, der Zunge, der Nase, der Hände und der Füße, das Riesenwachstum der Eingeweide (Leber, Herz), im Gegensatz zur niederen Statur des Individuums, der Hermaphroditismus und der Kopfschmerz gaben zusammen ein sehr klares, nosologisches Bild, dessen Identifizierung mit der Krankheit von Marie mir außer jeder Diskussion zu stehen scheint.

Hingegen komme ich gern auf die histologischen Einzelheiten des Hypophysistumors zurück, der, wie schon im ersten Falle, mit gutem Recht ein näheres Eingehen verlangt. Die mikroskopische Untersuchung zeigt auch hier von neuem, wie die Behauptung eines gänzlichen Fehlens von Hypophysisresten in einem gegebenen Tumor der Sella turcica in allen jenen

1) Schultz, Neurologisches Centralblatt 1889, 23, 24.

2) Sfameni, Lo Sperimentale. 1897. Fase, 1․ 
Fällen - und das sind die meisten - anfechtbar ist, in denen keine systematische, serienweise Untersuchung der verschiedenen Teile des Tumors stattgefunden hat. Wenn es sich um Tumoren beträchtlicher Größe mit Tendenz zur Ausbreitung und Zerstörung der Umgebung handelt, können die noch kaum erkennbaren Spuren der Hypophysis so gering sein, daß sie leicht der Beobachtung entgehen, In meinem Falle fand ich sie zur Not auf einigen 70 Schnitten, welche dem der Knochenwand des Türkensattels nächstliegenden Teil des Tumors angehörten.

So viel ich anch weiter forschte, konnte ich keine den Hypophysisschläuchen entsprechenden Bilder mehr finden, vielleicht auch wegen der leichten Vermorschung der Präparate infolge der langen Aufbewahrung in den Chromsalzen. Trotzdem genügten jene wenigen Präparate, um die Beziehungen zwischen dem Neoplasma und dem Drüsengewebe der Hypophysis klarzustellen und die nach jeder Hinsicht bedeutenden Unterschiede zwischen dem ersten und dem zweiten Falle zu zeigen. Während im Falle Schiav on die Abgrenzung zwischen Tumor und Vorderlappen deutlich war, und eine bindegewebige Schicht die zwei verschieden gearteten Gewebe voneinander trennte, war dafür im Fall Piziol das direkte Ubergehen der Hypophysisreste in den Tumor sichtbar. Im ersten Falle zeigte das Drüsengewebe eine durch Zusammenpressung verursachte schwere Atrophie: kleine Alveolen, dünne Zellstränge mit großenteils verschmolzenen Elementen in Form der sogenannten "Kernhaufen" (Rogowitseh), Fehlen der Chromophilzellen und Spärlichkeit der Colloidklumpen, zahlreiche, aber wie die Alveolen durch die Nähe des Tumors zusammengedrückte Blutgefäße. Im zweiten Fall dagegen fielen die Reste des Vorderlappens wegen des gut bewahrten schlauchartigen Aussehens sogleich in die Augen; es war dasselbe, welches die gesunde Hypophysis zwischen Hinter- und Vorderlappen aufweist. Die nur mit einer Schicht kubischen Epithels ausgekleideten Schläuche enthielten im Innern große Colloidklumpen. Die weiten, ganz nahe an den vorgenannten Schläuchen liegenden alveolären Räume, welche von dünnen und an Blutkapillaren reichen Bindegewebswänden begrenzt 
waren, und die im Innern zahlreiche, teils viele, teils spärliche Protoplasmakörnchen besitzende Zellen aufwiesen, halte ich für Teile des Hypophysisdrüsengewebes.

Immerhin darf man wegen der Ausdehnung dieser alveolären Räume, wegen der in ihrem Innern enthaltenen zahlreichen und hauptsächlich chromophilen Epithelzellen, diese Gewebsteile nicht für Reste des normalen Vorderlappens halten. Wir haben hier, nach meiner Ansicht, mit einem Gewebe zu tun, das alle Anzeichen der funktionellen Hypertrophie und Hyperplasie besitzt, welche im ersten Falle nicht gefunden werden. Dieses Gewebe kann tatsächlich als Utbergangszone zwischen dem normalen Organ und dem Tumor gelten. Im Gegensatz hierzu finden wir im Tumor selbst, in der Nähe dieser Ubergangszone, noch größere, von sehr dünnem Bindegewebe begrenzte and mit meist chromophilen Zellen vollgestopfte Alveolen und weiterhin Teile, wo das Bindegewebsnetz nur ein unterbrochenes, von spärlichen ungeordneten Fasern angedeutetes Aussehen hat. Bei oberflächlicher Untersuchung dieser Stellen und besonders der längs des Rückenmarkes verteilten und dem Mutterbodenganz unähnlichen metastatischen Knoten, könnte der Beobachter leicht in einen Irrtum verfallen und die Neubildung als Sarkom beurteilen. Nur durch Verfolgen des allmählichen Übergangs im primären Neubildungsherde, von den, Reste des normalen Hypophysisgewebes darstellenden Schläuchen, zu den geräumigen Alveolen, welche mit Zellen reich besetzt sind, die die morphologischen Eigenschaften der Hypophysiszellen zeigen, und von diesen Alveolen zu dem schon den Charakter der atypischen Neubildung tragenden Gewebe, gelangt man zur richtigen Ansicht über die Natur und Entstehung des Tumors.

In unserem Falle haben wir es mit einer adenomatösen Struma der Hypophysis mit vorgerückter krebsartiger Entartung zu tun. Ein guter Anhaltspunkt für die histologische Diagnose ist das Vorkommen von Chromophilzellen in den adeno-carcinomatösen Teilen des Tumors. Die Anwesenheit dieser Chromophilzellen ist ein klarer Beweis dafür, daß die aus Drüsen stammenden epithelialen Tumoren, wenn sie 
anch eine ausgesprochene idiopathische Wachstumsfähigkeit haben, doch Elemente aufweisen, die mehr oder weniger sich denen des Mutterbodens nähern. Vielleicht geschieht es aus diesem Grunde und weil man in neuerer Zeit die histologische Untersuchung mit größerer Umsicht ausgeführt hat, daß die als Hypophysissarkom bei Akromegalischen diagnostizierten Fälle sehr selten geworden sind. Wenn es erlaubt wäre, aus den Berichten über die neuesten Befunde ${ }^{1}$ ) ohne weiteres eimen Schluß zu ziehen, müßte er mit den Ansichten von Tamburini und Benda übereinstimmen, d. h. ergeben, daß die Hypophysistumoren bei Akromegalischen durch Adenome des Organs, oder durch einfache Hyperplasie hervorgerufen sind.

Was die sog. funktionierenden Adenome der Hypophysis anlangt, so vermute ich, daß einige der wegen der beinahe ausschlieBlichen Anwesenheit von Chromophilzellen in ihnen so klassifizierten Tumoren in Wirklichkeit wahrhaftige Hyperplasien des Organs sind, gleichwie auf anderem Felde gewisse Vergrößerungen z. B. der Prostata als Adenome diagnostiziert wurden, während sie für Hyperplasien angesehen werden müssen (Borst). In der Tat finde ich in den betreffenden histologischen Beschreibungen dieser sogenannten Adenome der Hypophysis vieles, was mich überzengt, daß sie große Âhnlichkeit mit jenen Tumorteilen meines zweiten Falles besitzen, die ich für ein strumöses Gewebe ansehe. Man könnte mir einwenden, daß der Untersehied zwischen Hyperplasie und Adenom oft schwer erkennbar ist, und daß jenes Gewebe, welches ich in meinem Tumor für hyperplastisch halte, hingegen adenomatös ist, während der von mir als adenematös beschriebene Teil sehon ein krebsartiges Gewebe darstellt. Demgegenüber bemerke ich, daß zu viele morphologische Anzeichen vorliegen, die mich veranlassen, die großen, mit Chromophilzellen und Colloid versehenen Alveolen für hyperplastische

1) Brooks (New-York Med. Journal, Bd. 65, 13, 1897); Hunter (British Med. Journal, $1898 \mathrm{~S}, 760$ ); Pfannenstiel och Josefson (Hygiea Bd. 65 S. 595, 1899); Meyers (Psych. en Neurol. Bladen. 1900); Caselli (1. c.) Ferrand (Soc. de Neurologie de Paris, 7. März 1901); Modena (Annuario del Manicomio Provinciale di Ancona 1903). 
Gebilde zu halten. Abgesehen von dem geringen Größenunterschied zwischen diesen Räumen und den normalen Alveolen der Hypophysis, welche mit der Auffassung, daß eine einfache Hyperplasie vorliegt, nicht unvereinbar ist, kann ich hier keine jener atypischen Bilder erkennen, welche das adenomatöse Gewebe auszeichnen. Das von Prof. Carbone beschriebene und von mir untersuchte Adenom zeigte außer dem auffallenden Fehlen der Chromophilzellen bedeutende Unterschiede gegen jene Bilder, welche ich für eine einfache hyperplastische Zone ansehe, während größere histologische Verwandtschaft mit jenen Teilen des Tumors Piziol vorhanden war, welche auch ich für adenomatöses Gewebe halte. Sowohl in diesen Teilen, wie auch in dem von Carbone beschriebenen Tumor fehlte das Colloid.

Um das Vorkommen von wenigen Chromophilzellen im adeno-karcinomatösen Gewebe (Fall Piziol) zu erklären, glaube ich annehmen zu müssen, daß die Bildung der Krebszellen. nicht durch rasche Umwandlung der Hypophysiszellen vor sich geht, sondern, wie natürlich, durch eine schrittweise Metamorphose derselben durch mehrere Zellengenerationen hindurch geschieht: eine der Wirkungen dieser Umwandlung mag in dem Verlust der protoplasmatischen Körnung zu Tage treten. Dadurch wird es erklärlich, wie so zwischen den ganz atypisehen Krebszellen wenige Elemente Stand halten können, welche nebst ihrer Form auch feinere Charakteranalogie mit den normalen Zellen des Mutterbodens besitzen. In den metastatischen Knoten längs des Rückenmarks, welche von atypischen Elementen gebildet werden, waren die Chromophilzellen aus diesem Grunde noch seltener als im adeno-karzinomatösen primären Krankheitsherde, und es fehlte in ihnen außerdem jede Spur von Colloidsubstanz. In zahlreichen Serienschnitten konnte ich diese dort nie finden.

Da ich der Ansicht bin, das Colloid sei das Sekret der Hypophysis and das letzte Umwandlungsprodukt der sogenannten "Sekretgranula“ - denn der Umstand, daß man es in der Hypophysis alter Leute vermehrt findet, kann auch nur eine Störung oder ein Hindernis in der Elimination dieses Stoffes durch physiologische Beeinträchtigung der bisher un- 
bekannten Ausführungswege bedeuten - kann ich auch an dem tatsächlichen funktionellen Zustand dieser da und dort in den adeno-karcinomatösen Herden verstreuten Chromophilzellen zweifeln. Es scheint mir erlaubt, anzunehmen, daß diese Zellen, obgleich sie die morphologischen Merkmale funktionierender Elemente besitzen, trotzdem die Fähigkeit verloren haben, ihre Sekretgranula in das endliche Sekretionsprodukt nämlich Colloid, umzuwandeln. Die adenomatöse Zelle (da als solche die zwischen Krebszellen befindliche Chromophilzelle angesehen werden muß) mag wohl dahin kommen, sich mit Granula zu füllen, aber diese besitzen schwerlich die chemisch-physiologische Beschaffenheit der normalen Granula; in diesen Zellen ginge also die funktionelle Störung der morphologischen Atypie voraus. Auf diese Weise erklärt sich der Umstand, daß im Adenokarzinom spärliche Chromophilzellen ohne Colloidsubstanz existieren. Benda konnte hierhin eine Bestätigung seiner Ansicht über die Bedeutung des Colloid finden, welches er, wie ich schon sagte, für ein Degenerationspropukt hält, aber ich denke, daß gegen ihn unter anderem das Vorkommen von Colloidklumpen in der Hypophysis von von mir untersuchten Menschenfötus spricht, wobei man kaum an einen sich abspielenden Degenerationsvorgang glauben darf.

Was die Natur des Hypophysistumors betrifit, halte ich dafür, daß der Fall Piziol Tamburinis Meinung bestätigt. In meinem Falle handelt es sich aller Wahrscheinlichkeit nach, ab initio, um eine an Chromophilzellen reiche hyperplastische Struma dex Hypophysis, welche beim späteren Fortsehreiten der Krankheit adeno-karcinomatösen Charakter angenommen hat. Uber die bösartige Natur der Geschwulst kann, nach der Konstatierung der zahlreichen metastatischen Knoten längs des Rückenmarks und seiner Verzweigungen in der Cauda equina, kein Zweifel walten.

Es ist nicht das erste Mal, daß man bei Akromegalisehen die Diagnose auf bösartigen Hypophysistumor stellt, aber diese Ansicht gründet sich nur auf den makroskopischen und histologischen Befund des primären Tumors und nie, so weit ich weiß, auf das Vorhandensein vom Krankheitsherd entfernter 
metastatischer Knoten. Diese Feststellung finde ich auch niemals bei Hypophysistumoren ohne Akromegalie erwähnt, so z. B. in dem alten Falle von Brodowski ${ }^{1}$ ), der nicht auf einen Akromegalischen Bezug zu haben scheint, und in dem neneren von Pechkranz ${ }^{2}$ ), wo sich eine Hypertrophie der weichen Teile der Glieder und des Gesichtes fand (Pachyacria mollis von Arnold), und wo nicht wirkliche Metastase existierte, sondern nur eine nach außen fortschreitende Ausbreitung des Hypophysistumors längs der Gehirnnerven (Oculomotorius and Optiens).

Wenn nun auch in unserem Falle die histologische Diagnose gut begründet ist, bleibt doch die Pathogenese des Tumors und seine Wichtigkeit mit Hinsicht auf das akromegalische Krankheitsbild in Dunkel gehüllt. Wenn man behauptet, daß ein Adenokarcinom sich auf einer hyperplastischen Neubildung der Hypophysis entwickelt habe, so ist dies für den Hirnanhang gleichbedeutend mit der schon für die Sohilddrüse erwiesenen Bestätigung der Tatsache, nach welcher man viele Adenokarcinome sich auf schon strumöser Schilddrüse entwickeln sah (Ewald). Immerhin bleibt die Ätiologie des Tumors unaufgeklärt.

Ist der Hypophysistumor die Ursache oder nicht vielmehr die Folge der Akromegalie? Handelt es sich um eine, in erster Zeit idiopathische Hyperfunktion der Hypophysis, welche den Stoffwechsel beeinflußt und an einigen Stellen des Skeletts einen abnormen Reiz auf die knochenbildende Tätigkeit des Periosts und vielfache andere Ernährungsstörungen hervorruft, oder ist es hingegen eine primäre Störung im Stoffwechsel, welche den Hypophysistumor und die Hyperplasie des Knochengerüstes später zur Folge hat?

Schon zu Anfang meiner Schrift habe ich die Gründe angeführt, welche mich mehr zur zweiten Hypothese hinneigen lassen; sie hat entschieden das Übergewicht, weun es sich um die Erklärung der anatomisehen Befunde in der Hypophysis bei Akromegalischen handelt, sei es, dab sie als einfache Hyper-

1) Brodowski, Protokolle der Sitzung der Warschaner Arztegesellschaft, 1878.

2) Pechkranz, Nenrologisches Centralblatt; 1899, S. 203. 
plasie, als nekrobiotische Erweichungen oder als Adenokareinome erscheinen. Ich nehme also an, daß in der Hypophysis besondere Bedingungen eintreten, welche das Organ mehr oder weniger für den Einfluß jenes Reizes empfindlich machen, der durch die starke Stoffwechselstörung entsteht. Auf diesen Reiz antwortet die Hypophysis nicht immer auf analoge Weise; manchmal degeneriert sie, manchmal reagiert sie gar nicht darauf (Israel), und in anderen Fällen kommt es za einer funktionellen Hyperplasie. $\mathrm{Zu}$ dieser letzteren Gattung mögen, wie ich bereits sagte, einige für funktionierende Adenome der Hypophysis gehaltene Fälle gehören. Es bleiben jedoch andere Fälle von Neoplasie der Hypophysis bei Akromegalischen übrig, für welche die Bezeichnung als Adenom gerechtfertigt scheint, und einige wenige, wie der. Fall Köhler von Benda und der meine, welche als Adenokarcinome anzusehen sind. Für diese letzteren scheint die Annahme einer vielleicht angeborenen Disposition des Organs am angemessensten; der Reiz wird auf ein zur Bildung des Tumors schon hinneigendes Gewebe ausgeübt, so daß dieser Reiz nicht die wahre, sondern die gelegentliche Ursache des Tumors ist. Der Hypophysistumor dieser Fäle ist in dieselbe Kategorie mit anderen zufällig bei der Autopsie von Akromegalischen gefundenen Neoplasien einzureihen; so zeigten sich im Falle von Caselli (a. a. O.) außer dem Adenom der Hypophysis zwei Tliacusmyxome and ein Osteosarkom der oberen Kinnlade; im Falle von Duchesnea ${ }^{1}$ ) eine neoplastische Entartung (Adenokarcinom?) der Schilddrüse; unter den von Virchow ${ }^{2}$ ) studierten fünf Skeletten von Akromegalischen fand sich bei einem ein großes Enchondrom in der unteren Epiphyse des Schenkelknochens, und schließlich im Falle von Pfannenstiel (a. a. 0.) existierte ein Gliom im rechten Mamillarkörper.

Der Einwand Pansinis ${ }^{3}$ ) gegen diese Theorie der primären Autointoxikation bei der Akromegalie ist, wie Vassale zeigt, von geringem Wert. Pansini hält die Ansicht für

1) Duchesneau, Contribution á l'étude anatomique et clinique de l'acromégalie etc. Thèse de Lyon, 1891.

2) Virchow, Berliner klin. Wochenschr. 1895, No. 50.

3) Pansini, Giomale internazionale delle Scienze Mediche, 1897. 
sonderbar, daß giftige Substanzen zur Hyperplasie des Skeletts, zu Phänomenen von Hyperernährung und Hyperfunktion des Periosts führen können. Er hat augenscheinlich nicht an die enormen Knochenvergrößerungen gedacht, welche bei Arbeitern, die mit Phosphor und mit Arsenik zu tun haben, vorkommen, und zwar gerade infolge von allgemeinen Vergiftungserscheinungen.

Mir scheint, daß diese Hypothese einer primären Intoxikation nicht nur alle ohne Hypophysistumor beobachteten Akromegaliefälle (welche Marie als solche nicht anerkennen will) und die wenigen Fâlle von teilweiser Akromegalie erklärt, sondern auch die lange Reihe von Beobachtungen, bei denen die durch den Hypophysistumor hervorgerufenen Symptome, trotz des empfindlichen Sitzes des Organes, viel später zum Vorschein kamen, als die akromegalischen Knochenveränderungen.

\section{Schlußfolgerungen.}

Im Vorstehenden habe ich, vom anatomisch-pathologischen Gesichtspunkte aus, zwei Fälle von Tumoren der Hypophysis beschrieben.

Im ersten Falle, bei dem sich keine akromegalischen Veränderungen zeigten, trat der weiche, schwammige, nußgroße Tumor aus der Sella turcica hervor und war, nach Zerstörung der Tubera cinerea und der Corpora mammillaria, in die Höhlung des dritten Ventikels eingedrungen und hatte seine Seitenwände angegriffen. Der histologisch als polymorphes teleangiektatisches Sarkom klassifizierte Tumor, schien nicht vom vorderen Abschnitt des Hirnanhangs auszugehen, weleher gegen den Boden der Sella gequetscht und in einen schmalen Streifen Drüsengewebe verwandelt war. In demselben fanden sich keine Chromophilzellen und nur sehr wenig Colloid.

Im zweiten Falle, der die von Marie beschriebenen typischen Veränderungen des Skelettes und einige andere Anomalien der Eingeweide (Makromyelie, Kardio- und Hepatomegalie) zeigte, hatte der Tumor der Hypophysis noch größere Verhältnisse angenommen, er hatte die Lamina quadrilatera des Keilbeins zerstört, eine oberflächliche Usur des Bodens der Sella 
turcica hervorgebracht und zahlreiche kleine metastatische Knoten längs des Rückenmarks erzeugt.

Die histologische Untersuchung ergab eine hyperplastische Struma mit vorgerückter adeno-karcinomatöser Entartung; in den kleinen strumösen Teilen fanden sich sowohl Colloidklumpen, als auch Chromophilzellen, welche ebenfalls mitten in den adenokarcinomatösen Teilen des Tumors sich zeigten.

Der erste dieser zwei Fälle beweist, daß eine auch bedeutende Verminderung der Funktion der Hypophysis keine akromegalischen Veränderungen verursacht.

Der andere, welcher, trotz der ausgedehnten und wahrscheinlich schon älteren bösartigen Degeneration der Geschwulst, auch in der letzten Zeit eine fortschreitende Vergrößerung der Extremitäten zeigte, spricht vielmehr zugunsten der Hypothese, daß die Akromegalie durch eine primäre Stoffwechselstörung entsteht, welche die Knochen des Schädels und der Glieder und manchmal mit Vorliebe die Hypophysis zu einer lebhaften hyperplastischen Neubildung reizt.

\section{Erklärung der Abbildungen auf Taf. II.}

Fig. 1. Fall Schiavon (siehe Textfigg. 1 und 2): a) Überreste des Vorderlappens der Hypophysis; b) Colloidsubstanzklümpchen; c) Teil des über den Hypophysisresten liegenden Tumors. Mittelstarke Vergrößerung.

Fig. 2. Fall Piziol (siehe Textfigg. 3 und 4) wie alle die folgenden Figuren: Überreste der Marksubstanz von Peremesko; a) Schläuche mit Colloidklumpen im Innern. Starke Vergrößerung.

Fig. 3. Strumöser Teil des Tumors: a) bindegewebiges Stroma, die Alveolen begrenzend; b) gefüllte Blutgefäße; c) Chromophilzelleu. (Koristka Oc. 2, Obj. 8).

Fig. 4. Querschnitt des unteren Dorsalteiles des Rückenmarks: a) neoplastische Umhüllung unter der GefäBhaut. 36 fache Vergrößerung.

Fig. 5. Metastatischer Knoten des Tumors längs eines Nerven der Canda equina. Der Tumor dringt, nach Zerstörung des Perineuriums, zwischen die Nervenfasern. a) Nervenast; b) isolierte und von Tumorzellen umgebene Nervenfasern; c) Chromophilzellen; d) blasse, chromophobe Zellen; e) Blutgefäß (Koristka Oc. 2, Imm. hom. $\frac{1}{12}$ ). 

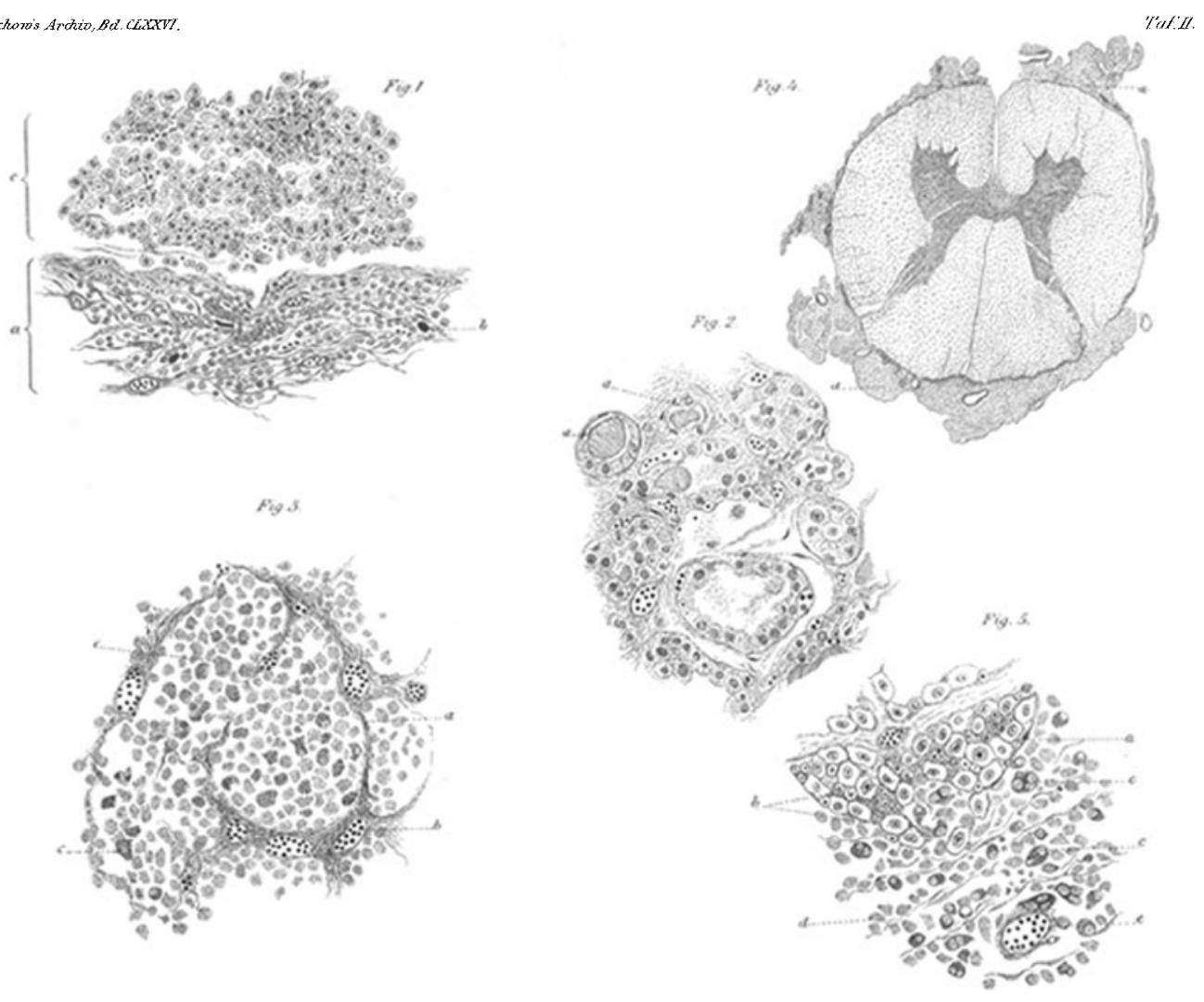

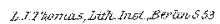

